\title{
Magnetic Characterization of Fischer-Tropsch Catalysts
}

\author{
P.A. Chernavskii , J.-A. Dalmon², N.S. Perov ${ }^{3}$ and A.Y. Khodakov4* \\ 1 Department of Chemistry, Moscow State University, 119992 Moscow - Russia \\ 2 Institut de Recherches sur la Catalyse et l'Environnement de Lyon, UMR 5256 CNRS, 2 avenue Albert Einstein, \\ 69626 Villeurbanne Cedex - France \\ 3 Department of Physics, Moscow State University, 119992 Moscow - Russia \\ 4 Unité de Catalyse et de Chimie du Solide, UMR 8181 CNRS, Bât. C3, USTL-ENSCL-EC Lille, Cite Scientifique, \\ 59655 Villeneuve d'Ascq - France \\ e-mail: chern@kge.msu.ru - jean-alain.dalmon@ircelyon.univ-lyon 1.fr - perov@magn.ru - andrei.khodakov@univ-lille1.fr \\ * Corresponding author
}

Résumé - La caractérisation par la méthode magnétique des catalyseurs Fischer-Tropsch Cet article passe en revue les développements récents dans le domaine de la caractérisation des catalyseurs Fischer-Tropsch à base de cobalt, de fer et de nickel par la méthode magnétique. La caractérisation magnétique fournit des informations précieuses sur la réduction du catalyseur, la taille des nanoparticules ferromagnétiques, la chimisorption, ainsi que sur les réactions topochimiques qui se produisent avec les catalyseurs au cours de la genèse de la phase active et dans des conditions réactionnelles. Les possibilités et les limites de la méthode magnétique sont examinées.

\begin{abstract}
Magnetic Characterization of Fischer-Tropsch Catalysts - This paper reviews recent developments in the application of magnetic methods for investigation of Fischer-Tropsch catalysts involving cobalt, iron and nickel. Magnetic characterization provides valuable information about catalyst reduction, sizes of ferromagnetic nanoparticles, chemisorption on ferromagnetics and topochemical reactions which occur with the catalysts during the genesis of the active phase and in the conditions of Fischer-Tropsch synthesis. The capabilities and challenges of the magnetic methods are discussed.
\end{abstract}




\section{INTRODUCTION}

The increasing interest in Fischer-Tropsch synthesis has been instigated by the growing demand for clean fuels and utilization of abundant natural gas, coal and biomass-derivated synthesis gas [1-3]. The sub-ferrous metals (cobalt, iron and nickel) are the most active catalysts for carbon monoxide hydrogenation. Both cobalt and iron have been used at the industrial scale as catalysts for Fischer-Tropsch synthesis (South Africa, Malaysia, Qatar, etc.). Consequently, a growing number of works have focused on investigation of the structure of these catalysts. Much of this interest is due to industrial requirements, such as optimization of catalyst activity, selectivity and stability.

The challenges in the investigation of these catalysts are usually due to the relatively high reactivity of small metal and oxide particles. First, chemical interaction of metals and oxides with a catalytic support $\left(\mathrm{Al}_{2} \mathrm{O}_{3}, \mathrm{SiO}_{2}, \mathrm{TiO}_{2}\right.$, etc. $)$ has to be taken into consideration [4]. Secondly, it is known that small metal particles can easily interrelate with the reacting medium; thus, they can be involved in a wide range of topochemical processes on the catalyst surface. According to IUPAC, a topochemical reaction [5] is a reversible or irreversible reaction that involves the introduction of a guest species into a host structure and that results in significant structural modifications to the host; for example, the breakage of bonds. For metal catalysts in the conditions of FischerTropsch synthesis, the topochemical reactions can include oxidation of metal particles by trace amounts of oxygen and water, carburization, sintering, formation of nitrides and sulfides, etc. It is clear that development of efficient catalytic processes would require more complete information about the topochemical reactions involving small oxide and metal particles which proceed during catalyst preparation and catalytic reaction. These reactions can often alter the catalytic performance.

Unfortunately, most of the conventional characterization techniques do not always provide comprehensive data on topochemical processes which involve nanoparticles. In particular, extracting in situ and operando information about evolution of the catalyst structure during different pretreatments and the Fischer-Tropsch reaction represents significant difficulties. Measurements of particle size or metal dispersion in metal catalysts seem to be another challenge to overcome. Comparative analysis of different characterization methods of cobalt-supported Fischer-Tropsch catalysts was conducted in our recent publication [1].

Application of magnetic methods has proven to provide very efficient solutions to the many problems associated with metal-supported catalysts involving ferromagnetic metals such as $\mathrm{Fe}, \mathrm{Co}$ and $\mathrm{Ni}$ [6-8]. This present work addresses recent developments in magnetic characterization of metallic Fischer-Tropsch catalysts. Attention will be primarily focused on measurements of magnetization of ferromagnetic phases. The magnetic resonance techniques, such as nuclear magnetic resonance, electron spin resonance or ferromagnetic resonance are beyond the scope of the present review.

\section{NON-RESONANCE MAGNETIC METHODS OF CATALYST CHARACTERIZATION}

The conventional methods of studying magnetic properties of solids and liquids can be divided into two groups: static methods and dynamic methods. Both these methods can be applied to heterogeneous catalysts. Note, however, that specificity of catalytic materials introduces some specific requirements for both experimental conditions and magnetometric equipment. Thus, for evaluation of catalyst structure the magnetic measurements should be possibly conducted in situ in a controlled environment and at a wider range of temperatures (from the temperature of liquid helium to $1000 \mathrm{~K}$ ). In addition, because of the presence of small superparamagnetic particles in the catalysts, the magnetic field should have high strength (up to $100 \mathrm{kOe}$ or $8.96 \times 10^{7} \mathrm{~A} / \mathrm{m}$ ). Therefore, it appears that all-purpose magnetometers are not very convenient and have to be modified for investigation of the structure of heterogeneous catalysts. Below is a brief description of the most common static and dynamic methods for measuring catalyst magnetization.

The static methods are usually based on the Faraday equation. In the static method, a sample is placed in the area of constant gradient of the magnetic field. The gradient of the magnetic field is calibrated using a sample with known magnetization. The force applied to the sample is measured according to the equation:

$$
F=\chi \cdot V \cdot H \cdot\left(\frac{d H}{d x}\right)
$$

where $\chi$ is the magnetic susceptibility, $V$ is the sample volume, $H$ is the magnetic field strength, $d H / d x$ is the gradient of the magnetic field along the $x$ axis; the $x$ axis can be vertical (rocker balance) and horizontal (pendulum balance). The schema of the Faraday rocker balance is presented in Figure 1. Typically, the space between the magnetic poles is very small, because it is undesirable that the sample be subjected to magnetic fields of very different strengths.

The Faraday method has several limitations. First, the Faraday method is inconvenient for measuring the dependence of magnetization on the magnetic field. While the magnetic field is changing between the poles, its gradient is changing as well. This makes it difficult to calibrate the sensitivity of the installation. Secondly, it is known that for all substances, the magnetic moment is a function of the field strength. In the Faraday method it is essential that the sample has to be placed in an inhomogeneous field. The magnetic moment is a function of the sample size. For ferro- and ferrimagnetics, the variation in magnetic moment 


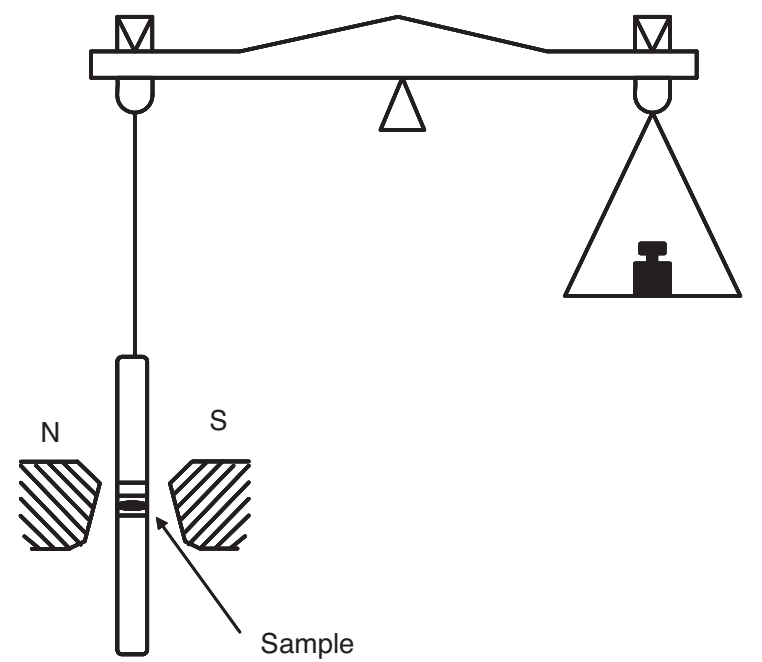

Figure 1

Schema of Faraday rocker balance.

with magnetic field can be significant and therefore it can affect the quality of experimental data. Thirdly, typically a large volume of the Faraday balance makes it difficult to study evolution of catalyst structure and sample magnetization during the pretreatments and catalytic reactions, in particular in transient conditions.

The dynamic methods involve measurements of the voltage which arises in the coils placed next to the sample during its displacement in the magnetic field (due to the variation in magnetic flux in the coils). This voltage is proportional to the magnetic moment of the sample. The Weiss and Foner methods are two different variants of the dynamic magnetic method. Of these two methods the Weiss extraction method [9] has been most widely used. In the Weiss method the sample is placed in a uniform field between the magnet poles (Fig. 2). The Helmholtz induction coil is located next to the sample. This coil is connected to the measuring equipment. During the measurements the sample is sharply displaced in the uniform magnetic field. The magnetization is evaluated from the voltage which occurs in the coil during the sample displacement. In the state-of-the-art Weiss magnetometers, the accuracy of measurements has been improved by averaging the results produced by a series of identical sample displacements.

In the Foner method (also called a vibrating sample method [10]), the sample vibrates in the magnetic field with the sound frequency. The simplified schema of a Foner magnetometer is shown in Figure 3. The voltage arising in the pick-up coils is proportional to the magnetic moment of the

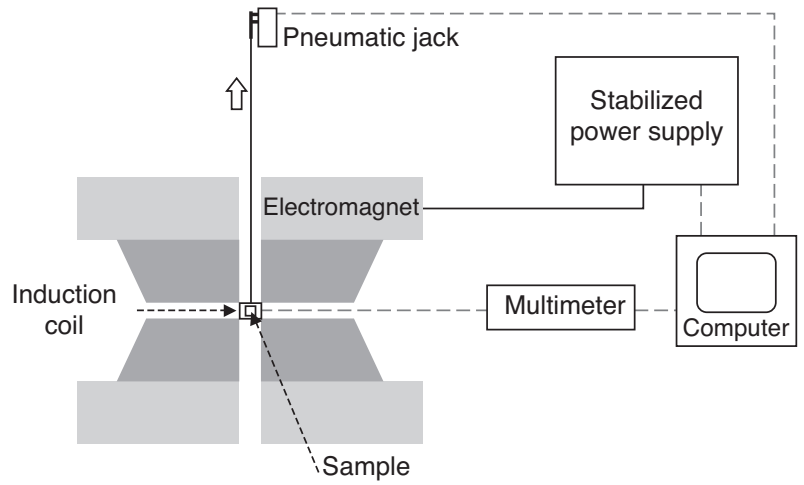

Figure 2

Schematic drawing of Weiss extraction magnetometer. The sample magnetization is obtained from the current induced in the coil during the extraction of the sample.

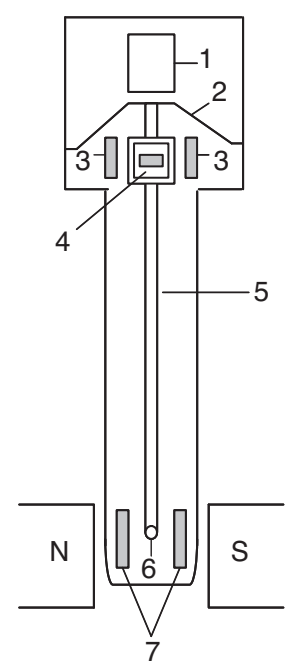

Figure 3

Simplified schema of Foner magnetometer: (1) sound generator, (2) horn, (3) reference coil, (4) reference sample of constant magnetization, (5) non-magnetic bar, (6) sample, (7) pick-up coil.

sample. Both the Weiss and Foner methods have the same physical background; the Foner method differs from the Weiss method only in data processing. Because of the possible generation of Foucault currents during the sample vibration, the Foner method is not well suited for studying conducting materials. In metal-supported catalysts the Foucault currents are not usually produced because the metal particles are electrically isolated from each other. The Foner method has great potential for studies of catalysts containing ferri- or ferromagnetic phases [11]. Despite several obvious advantages, the Foner method has not been widely disseminated. 


\section{PROBLEM OF SMALL PARTICLES: SINGLE-DOMAIN PARTICLES AND SUPERPARAMAGNETICS}

The domain structure of bulk ferromagnetics corresponds to the minimum of its total energy [12]. The total energy of ferromagnetics constitutes:

- the electron exchange energy, which is minimal when all electron spins are parallel,

- the energy of crystalline anisotropy due to the existence of crystal axes of "easy" and "difficult" magnetization (because of dipole-dipole interaction of magnetic moments of individual atoms),

- the magnetostatic energy related to the presence of magnetic poles inside and on the surface of the sample

- the magnetostriction energy caused by changes in the domain size due to the changes in magnetization and its orientation.

The presence of magnetic domains usually reduces the number of poles in the sample and related magnetostatic energy. The domains are areas of ferromagnetics spontaneously magnetized to saturation. The domains are mostly located along the axes of "easy" magnetization.

Bulk ferromagnetics consists of a large number of domains. The situation is different with smaller particles of ferromagnetics. Frenkel and Dorfman [13] first predicted that small particles of ferromagnetics might have a single-domain structure. When the particle diameter decreases, the magnetostatic energy which is proportional to the volume decreases faster than the energy of the boundaries between domains which is proportional to the surface. At some particle size, the single-domain ferromagnetic structure becomes favored over the multidomain one. Kondorskii developed a rigorous theory of single-domain particles $[14,15]$. In this theory an upper limiting or critical radius, $R_{c}$, of the area which has uniform magnetization is defined as:

$$
R_{c} \approx \frac{0.95}{I_{s}}(10 \cdot A)^{1 / 2} \cdot\left(Q-\frac{2 K}{I_{s}^{2}}-\frac{H}{I_{s}}\right)^{-1 / 2}
$$

where $I_{s}$ is the saturation magnetization, $A$ is the parameter of exchange energy, $K$ is the anisotropy constant, $Q$ is the factor of demagnetization and $H$ is the field strength. Note that the particles which radius satisfies Equation (2) have a singledomain structure for the values of the field $H>-\frac{2 K}{I_{s}}$. The condition of the absolute single domain (in all magnetic

fileds) is:

$$
R<R_{c} \approx \frac{0.95}{I_{s}} \cdot\left(\frac{10 \cdot c \cdot B}{a_{0} \cdot Q_{R}}\right)^{1 / 2}
$$

where $c=1 / 2 ; 1 ; 2$ for, respectively, simple cube, volumecentered and face-centered cubic lattices; $B=z^{2} A$ is the parameter of exchange energy; $z$ is the number of uncompensated spins per atom, $A$ is the exchange integral, $a_{0}$ is the crystal lattice parameter, and $Q_{R}$ is the demagnetization factor of the single-domain ellipsoid along the short axis. Equation (3) yields the upper estimation of the critical radius of singledomain particles. The evaluation of the single-domain critical size has been discussed in a number of reviews [16, 17]. The critical diameter of spherical single-domain ferromagnetic particles is $20 \mathrm{~nm}$ for cobalt [12, 18], $14 \mathrm{~nm}$ for iron, $55 \mathrm{~nm}$ for nickel, $128 \mathrm{~nm}$ for $\mathrm{Fe}_{3} \mathrm{O}_{4}$ and $166 \mathrm{~nm}$ for $\gamma-\mathrm{Fe}_{2} \mathrm{O}_{3}$ [19].

As the ferromagnetic particles approach the single-domain state, the synchronic (coherent) rotation of individual atomic magnetic moments becomes the predominant mechanism of remagnetization. This process is hindered by crystalline anisotropy and shape anisotropy. In order to remagnetize the single-domain spherical particle through coherent rotation, it is necessary to apply the opposite magnetic field:

$$
H_{c, \text { max }}=2 K_{e} / I_{s}
$$

where $H_{c \text {, max }}$ is the maximum coercive force, $I_{s}$ is the saturation magnetization and $K_{e}$ is the full anisotropy constant. Several experimental studies of the relations between coercive force and particle size [18, 20-21] have been conducted in the literature. This relation can be qualitatively illustrated by Figure 4 .

As the particle radius decreases, the inter-domain boundaries become energetically unfavorable and the particle turns into a single-domain one. Typically, a single-domain particle of upper critical size has the maximal coercive force. Increase in particle size leads to multidomain ferromagnetic structure and to a decrease in coercivity. Finally, when the particles become very large, the coercivity attains the value characteristic of bulk ferromagnetics.

For single-domain particles, the change in magnetization can no longer be assigned to the displacement of interdomain boundaries, but it should be attributed to the coherent

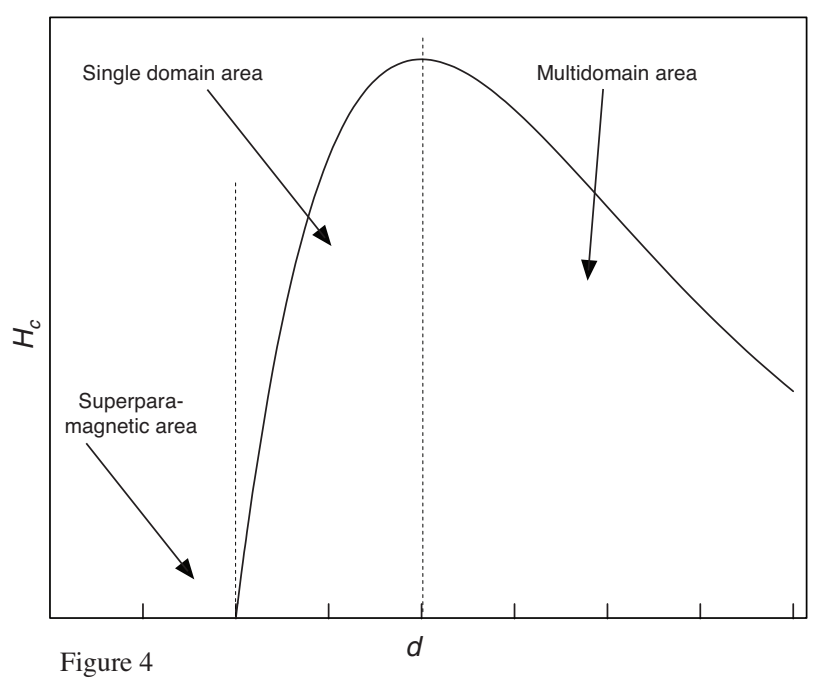

Qualitative relation between the coercive force and particle size. 
rotation of atomic magnetic moments. Uniform magnetization is still present in the single-domain particles of smaller size, since the atomic moments are held by the exchange forces in the parallel direction.

Decrease in particle volume leads to higher probability of Brownian motion of the total magnetic moment: $M=V I_{s}$. Note that the magnetic moment rotation is an activated process with the activation energy, $E$. The total magnetization, $I=N M_{i}$, of the ensemble of $N$ particles after switching off the magnetic field drops to zero because of Brownian motion of magnetic moments, $M_{i}$, of individual particles. The relevant decrease in magnetization follows the law:

$$
I=I_{s} \cdot \exp (-t / \tau)
$$

where $t$ is the time and $\tau$ is the relaxation time. Thus, the small particles behave like an ensemble of paramagnetic atoms which has a large magnetic moment, $M$. This phenomenon, called "superparamagnetism", has been extensively studied both theoretically [22], and experimentally [23-24]. The theory suggests that the relaxation time, $\tau$, depends on the energy barrier, $E$ :

$$
\tau=\tau_{0} \exp \left(\frac{E}{k_{B} T}\right)
$$

where the $\tau_{0}$ parameter is typically between $10^{-9}$ and $10^{-10} \mathrm{~s}$. The energy barrier is $E=K V$; it depends on the anisotropy constant and particle volume. Therefore, according to Equation (6), $\tau$ depends on both particle volume and temperature.

The particles become superparamagnetic when their diameter is smaller than the critical diameter, $D_{c}$. In fact, superparamagnetism is a special case of ferromagnetism where particle magnetic moment, magnetic field and temperature are in thermodynamic equilibrium. As a result, superparamagnetic materials do not exhibit a stable residual magnetization. In order to facilitate things, in the present manuscript we will call particles whose diameter is larger than the critical diameter, $D_{c}$, ferromagnetic particles, and those with diameter under $D_{c}$ superparamagnetic particles.

The upper critical sizes of superparamagnetic particles for different metals can be easily estimated assuming $\tau$ to be equal to $10^{-9} \mathrm{~s}$. For example, for iron particles with a diameter of $30 \mathrm{~nm}$ at $T=300 \mathrm{~K}$ the relaxation time is $\tau \approx 4 \times 10^{6} \mathrm{~s}$ but with the iron particles $(D=23.8 \mathrm{~nm})$ with twice as small a volume the relaxation time $\tau$ would be $6 \times 10^{-2} \mathrm{~s}$. Increase in temperature also results in decrease in the relaxation time. Thus, iron particles with a diameter of $23.8 \mathrm{~nm}$ or less at room temperature will lose their magnetization and would reach thermal equilibrium for less than one tenth of second, and consequently they exhibit superparamagnetic properties. At the same time, the iron particles of $30 \mathrm{~nm}$ at room temperature are extremely stable, and will behave like singledomain ferromagnetics. These $30 \mathrm{~nm}$ particles, however, which are ferromagnetic at room temperatures, will transform into superparamagnetic at $T=600 \mathrm{~K}$.
Note that all ferromagnetic particles lose their magnetization with time. Generally speaking, ranking particles into ferromagnetics and superparamagnetics depends only on the time of observation. Usually, in static measurements $\tau$ is suggested to be equal to $100 \mathrm{~s}$. This evokes that the transition between the ferromagnetic and superparamagnetic states occurs when the following condition is fulfilled:

$$
K V=25 k_{B} T
$$

where $K$ is the anisotropy constant, $k_{b}$ is Boltzmann's constant, $V$ is the volume of the particles and $T$ is the temperature of measurements. If the particle volume is larger than $V>\frac{25 k_{B} T}{K}$, the particle is a ferromagnetic and it has a residual magnetic moment; if the particle volume is smaller than $V<\frac{25 k_{B} T}{K}$, the particle is a superparamagnetic.

In the external magnetic field, $H$, the particles acquire additional energy, which could affect the energy barrier, $E$, and hence relaxation time. In [25] the expression has been obtained for the coercive force $H_{c}$ which would disorientate magnetic moments, $M_{i}$ of particles of $V$ volume for $100 \mathrm{~s}$ :

$$
H_{c}=\frac{2 K}{I_{s}}\left[1-7\left(\frac{k_{B} T}{K D^{3}}\right)^{1 / 2}\right]
$$

At $T=0 \mathrm{~K}$ Equation (7) yields $H_{c}=2 K / I_{s}$, and at $T=$ $K V / 25 k_{B}$ it gets $H_{c}=0$. Equation (7) allows the calculation of the critical volume of superparamagnetic particles, $V_{c}$ by extrapolating coercive force as a function of $D$ to the value $H_{c}=0$. By substituting temperature and $V_{c}$, one can calculate $2 K / I_{s}$. It should be borne in mind, however that according to recent data, the anisotropy constant, $K$, also depends on the particle size [26]. The "core-shell" theory [27] has been proposed to explain this phenomenon. This theory considers differently the contributions to the energy barrier, $E$, coming from superficial and inner particle atoms. Obviously, the relative contribution of superficial atoms decreases with increase in particle size, and correspondingly growth in the ratio of the number of superficial atoms to the total number of atoms in a particle. It was also [28] suggested that in the systems which constitute ultra-dispersed particles, the energy, $E$, was only a function of superficial atoms and did not much depend on the particle volume.

When anisotropy can be neglected $\left(k_{B} T>>K V\right)$, the orientation of the magnetic vector can randomly evolve under the influence of thermal fluctuations. Hence the particle does not exhibit ferromagnetism. Consequently, the hysteresis loop turns into a sigma-shaped curve, i.e. both coercive force and residual magnetization become equal to zero. In this case, the dependence of the magnetization on the magnetic field can be described by the Langevin formula:

$$
I=I_{s}\left(\operatorname{cth} \frac{M H}{k_{B} T}-\frac{k_{B} T}{M H}\right)
$$


Decomposition of the hyperbolic cotangent into a series assuming that $M H>>k_{B} T$ leads to:

$$
I \approx I_{s}\left(1-\frac{k_{B} T}{M H}\right)
$$

while at $M H<<k_{B} T$, it gives:

$$
I \approx I_{s} \frac{M H}{3 k_{B} T}
$$

When the particle size distribution is defined by a function $f(V) d V$, the full magnetization of the sample with $V_{0}$ volume is determined by:

$$
I=I_{s} V_{0} \int_{0}^{\infty}\left(c t h \frac{I_{s} V H}{k_{B} T}-\frac{k_{B} T}{I_{s} V H}\right) f(V) d V
$$

Equation (11) suggests that the particle size distribution curve can be extracted from the dependence of magnetization on the magnetic field. Equation (11) also suggests that the field dependences measured at different temperatures for superparamagnetic particles should coincide when they are plotted as I versus $H / T$. Approximate coincidence of magnetization curves expressed via the $H / T$ ratio is an important feature of superparamagnetism.

\section{METHODS OF MAGNETIC GRANULOMETRY}

Since determination of the metal average particle size and particle size distribution is a very important task for description of the structure and catalytic performance of metal-supported catalysts, let us discuss in greater detail methods of magnetic granulometry. Equations (9-11) provide tools for measuring the average particle size, $D$, and particle size distribution, $f(D)$. For weak magnetic fields (small $H / T$ ratio) the following expression for the particle size can be obtained from Equation (10):

$$
D_{1}=\left[\left(\frac{I}{H}\right) \cdot\left(\frac{18 k_{B} T}{\pi \rho I_{s}^{2}}\right)\right]^{1 / 3}
$$

Similarly, for strong magnetic fields (high $H / T$ ratio) Equation (9) gives:

$$
D_{2}=\left[\frac{6 k_{B} T}{\left(I_{s}-I\right) \pi \rho H}\right]^{1 / 3}
$$

where $\rho$ is the metal density. Since the dependence of the magnetization on the field for weak fields $(H / T \rightarrow 0)$ is principally affected by the presence of larger particles, Equation (12) gives estimation of the upper particle size, $D_{1}$. Accordingly, the magnetic behavior close to saturation at stronger fields is mostly controlled by smaller particles; Equation (13) specifies the lower values of the particle size. Equations $(12,13)$ have been used previously [29-31] for evaluation of the particle size in nickel-supported catalysts.
In previous report [7] a method was proposed for calculating the particle size distribution. In this method, Equation (11) was presented as:

$$
\frac{I}{I_{s}}=\sum_{n=0}^{\infty} g(n) \cdot L(n, H)
$$

where $L(n, H)$ is the Langevin function, $\mathrm{n}$ is the selected interval of $D$ values and $g(n)$ is the mean value of $f(D)$ at the specified interval. For given values of the field $H$ the following system of equations can be written:

$$
\begin{aligned}
& \left(\frac{I}{I_{s}}\right)_{H_{1}}-g\left(D_{1}\right) \cdot L\left(D_{1}, H_{1}\right)+g\left(D_{2}\right) \cdot L\left(D_{2}, H_{1}\right)+\ldots .=y_{1} \\
& \left(\frac{I}{I_{s}}\right)_{H_{2}}-g\left(D_{1}\right) \cdot L\left(D_{1}, H_{2}\right)+g\left(D_{2}\right) \cdot L\left(D_{2}, H_{2}\right)+\ldots=y_{2}
\end{aligned}
$$

To obtain $g\left(D_{i}\right)$ the system of Equations (15) can be solved using a standard software-based Newton-Raphson algorithm. The initial values, $g\left(D_{i}\right)$, for the iterative procedure are defined from the minimum $Q=\sum_{n} y_{n}^{2}$. A $\log$ normal distribution function can be used as the initial approximation. It was shown [32] that this method gives good results even for a bimodal distribution.

Note, however, that the final result is usually strongly affected by the choice of initial conditions, i.e. initial particle size distribution. In fact, we are faced here with a reverse problem which is well known in both physics and physical chemistry. It should be stressed that this method requires very strong fields (up to $100 \mathrm{kOe}$ ), which are achievable only using superconducting solenoids. The stronger is the field, the more accurate is the determination of value of the saturation magnetization. In addition, accurate measurements of $I_{s}$ should be conducted at lower temperatures close to the temperature of liquid helium. For particle size smaller than $2 \mathrm{~nm}$, determination of $I_{S}$ represents a very difficult task.

Potton et al. [33] proposed a technique which can circumvent these difficulties by applying the method of maximum entropy and using an algorithm from [34]. The method of maximum entropy can successfully meet this challenge without specifying the initial shape of particle size distribution. The method consists of searching for the maximum of the expression:

$$
S=-\sum_{j=1}^{N} f_{j} \ln \left(\frac{f_{j}}{b_{j}}\right)
$$

where $f_{j}$ is the distribution function and $b_{j}$ is the initial value of $P$ :

$$
P=\sum_{i=1}^{P} \frac{\left(I_{i} / I_{s}-y_{i}\right)}{\sigma_{i}^{2}}
$$




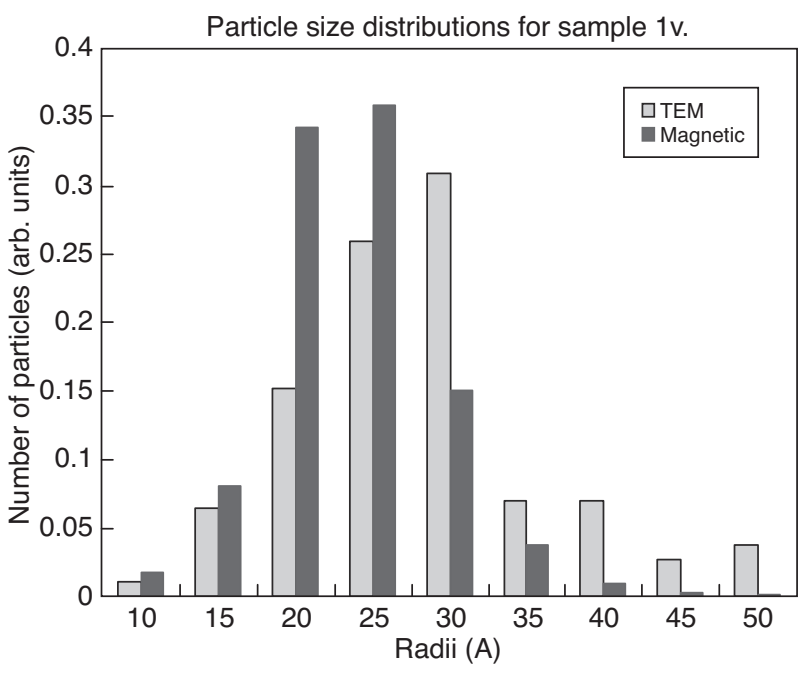

Figure 5

Comparison of $\mathrm{Co} / \mathrm{SiO}_{2}$ particle size distributions from TEM and magnetic measurements.

In Equation (17) the summation is conducted over all measurements at a given point, $\sigma_{i}^{2}$ is dispersion for each point, and values $I_{i}$ and $y_{i}$ are defined by a system of Equations (15). Thus, to solve Equations (15) both the physical model which involves the Langevin equation and experimental dependence of magnetization on the magnetic field are required. It is important to note that the obtained solution would not involve any initial predefined distribution of particle size and any predefined value of $I_{s}$. The saturation magnetization, $I_{s}$, can be estimated from normalization of function $f$. The method of maximal entropy was successfully applied [35] for determination of the size distribution function of $\mathrm{Ni}$ particles in $\mathrm{Ag}-\mathrm{Ni}$ alloy. It was also shown [36] that the method can be very efficient, particularly in the analysis of bimodal distribution. Potton's method was also used to follow particle size distribution in silica-supported cobalt catalysts. While the results obtained by the magnetic method were qualitatively consistent with TEM data (Fig. 5), electron microscopy seems to slightly overestimate cobalt particle size [37].

Another technique to measure particle size distribution was suggested by Weil. This method involves measurements of residual magnetization as a function of temperature. The method is based on the fact that the residual magnetization at a given temperature should be principally affected by the particles which are larger than the upper critical size of superparamagnetics. Using this approach, Weil [23] studied Ni powder and obtained bimodal distribution, which was attributed to the influence of preparation conditions on the nickel particle size. The Weil method

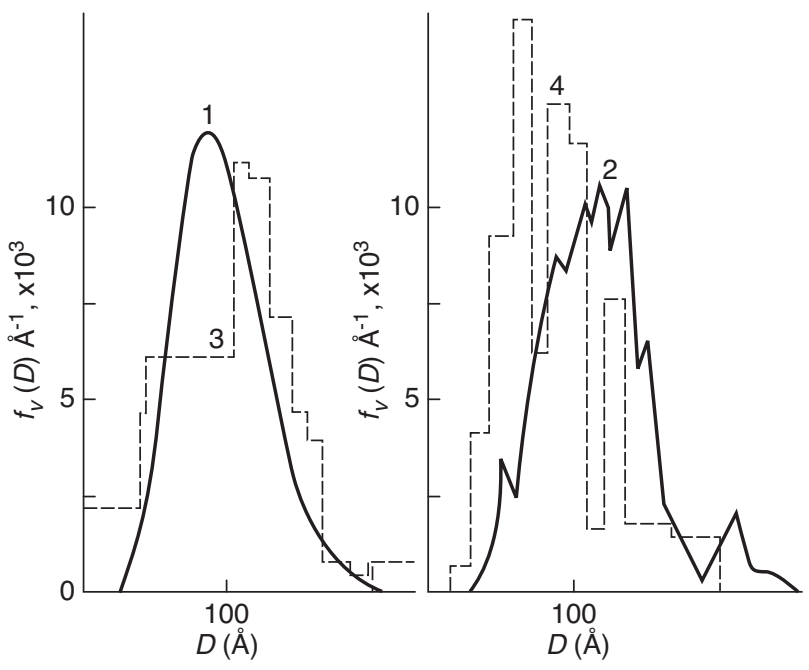

Figure 6

Volume particle size distributions of a $\mathrm{Ni} / \mathrm{SiO}_{2}$ sample. Curves: (1) from the magnetization curve, (2) transmission electron microscopy, (3) small-angle X-ray scattering, (4) Weil method (temperature range 300-2.4 K).

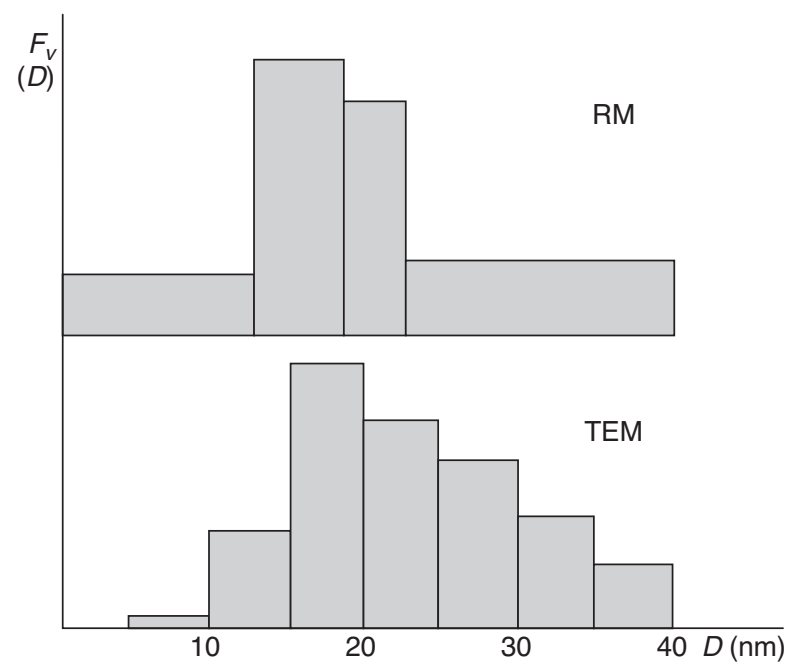

Figure 7

Volume particle size distribution of a $\mathrm{Co}(37 \mathrm{wt} \%) / \mathrm{SiO}_{2}$. Weil (or Remanence Method, RM), top. Transmission Electron Microscopy (TEM), bottom.

was also used to calculate particle size distribution in $\mathrm{Ni} / \mathrm{SiO}_{2}[38]$ and $\mathrm{Co} / \mathrm{SiO}_{2}$ [39] catalysts. The volume-base particle size distributions obtained by the Weil method and other characterization techniques are shown in Figure 6 [38] and Figure 7 [39].

The methods for measuring particle size distribution, which are discussed above, suggest that particles behave 
independently of each other. Meanwhile, the effects of interaction of particles in real systems can significantly affect the apparent magnetic properties. First, the interparticle interaction is reflected in an inability to combine magnetic curves measured at different temperatures for superparamagnetic particles, but expressed via $H / T$ ratios. Let us evaluate the validity of the theories discussed above in the context of particle-particle interaction.

The energy of dipole-dipole interaction between particles with a magnetic moment, $M$, could be estimated using the expression [40]: $E_{\text {int }}=M / R^{3}$ where $R$ is the distance between the particles. For a system of superparamagnetic particles with a diameter $D=10 \mathrm{~nm}$ and situated at a distance of $2 D$ from each other, from equation $E_{i n t}=k T$ it follows that dipole-dipole interaction would be stronger than the thermal fluctuations at $300 \mathrm{~K}$.

Let us consider a system consisting of $N$ superparamagnetic spherical particles with an average radius, $r$, located on the surface of porous media with pore volume $V_{p o r}$. Let us also assume that distribution of metal particles on the surface of the substrate is Poisson's (the most common physical considerations suggest that this can be the case). Thus, the distribution function of the distances from the center of one particle can be written as [41]:

$$
f(l)=4 \pi \cdot l^{2} \cdot \lambda \cdot \exp \left(-\lambda \frac{4}{3} \pi \cdot l^{3}\right)
$$

where $\lambda=N / V_{\text {por }}$ is the number of particles in the elementary volume of porous support. The average distance between the particles is calculated as follows:

$$
\bar{l}=4 \pi \lambda \int_{0}^{\infty} l^{3} \cdot \exp \left(-\lambda \frac{4}{3} \pi \cdot l^{3}\right) d l
$$

After integration, it appears that: $L \approx 0.55 \cdot\left(V_{p o r} / N\right)^{1 / 3}$ and consequently $E_{\text {int }} \approx 0.17 M N / V_{\text {por }}$. The resulting expression allows the calculation of the energy of dipole-dipole interaction for a specific metal-supported catalytic system.

It should be noted that the techniques of magnetic granulometry which were described above are applicable only to the ensemble of superparamagnetic particles. If the system in addition to superparamagnetic particles contains single-domain ones, the determination of particle size distribution becomes more complicated. In this case, the following approximate expression can be used for estimating the fraction of superparamagnetic particles:

$$
\gamma=1-2 \sigma_{r} / \sigma_{s}
$$

where $\sigma_{r}$ is residual magnetization and $\sigma_{s}$ is saturation magnetization [29]. However, it should be noted that the estimation is valid only provided that the system does not contain multidomain ferromagnetic particles. For cobaltcontaining systems it means in particular that the sample does not contain particles with $D \geq 20 \mathrm{~nm}[12,18]$. Naturally, the question arises: how can one prove that the system does not contain particles larger than the upper criti- cal size of single-domain particles? Recently we proposed a relatively easy way to "eliminate" the systems containing multidomain ferromagnetic particles with $D>D_{c r}$. [42].

Low-temperature oxidation of metals $(T<600 \mathrm{~K})$ usually proceeds via formation of thin oxide films on the surface of metal particles. The formation of these films reduces the apparent size of relevant metal particles. If measurements are taken at temperatures above the Néel temperature of metal oxides, when the magnetic exchange interactions at the boundaries between oxide and metal can be neglected, the qualitative dependence of the coercive force on the particle size (Fig. 4) remains valid. Therefore, if $D>D_{c}$, then mild oxidation would lead to an increase in coercive force, $H_{c}$. Otherwise, if $D<D_{c}$, then the coercive force would decrease as a result of the oxidative treatment.

Recently, we proposed [43] a method for granulometric analysis of systems based on the hysteresis loop. Below is an example of this analysis conducted with a system containing cobalt metal particles. The relevant field dependence curve measured using an experimental setup described elsewhere [44] is shown in Figure 8. The shape of the field dependence indicates the presence of two types of cobalt metal particles. The presence of residual magnetization is probably due to "larger" cobalt single-domain ferromagnetic particles, while non-saturation of the hysteresis loop in the strong magnetic field $(H=8000 \mathrm{Oe})$ is indicative of "smaller" superparamagnetic ferromagnetic particles.

The behavior of superparamagnetic particles in the magnetic field is described by the Langevin function [45].

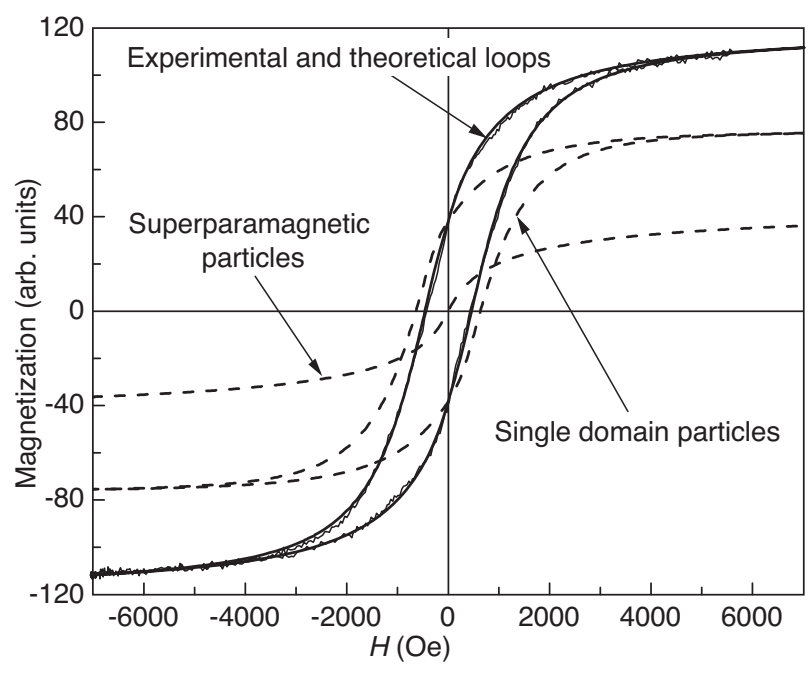

Figure 8

Typical experimental and calculated hysteresis loops for a fine Co particle system, illustrating the theoretical approach presented in the text. 
For calculation of the particle size distribution of "larger" particles, we will suppose that all ferromagnetic particles have single-domain structure, spherical shape and uniaxial anisotropy. The well-known Stoner and Wohlfarth model [20] for non-interacting single-domain particles with uniaxial magneto-crystalline anisotropy and the axis of "easy" magnetization oriented randomly in space is used for description of "larger" ferromagnetic particles.

The weights $\alpha$ and $\beta$ of the superparamagnetic and singledomain particle distribution, correspondingly, can be found using a normalization condition and the condition of proportionality of volumes of two fractions of particles to their saturation magnetizations $M_{s}^{(1)}$ and $M_{s}^{(2)}$ :

$$
\alpha+\beta=1, \quad \frac{\alpha V_{1}}{\beta V_{2}}=\frac{M_{s}^{(1)}}{M_{s}^{(2)}}
$$

where $V_{1}$ and $V_{2}$ are the volume of the corresponding fractions.

The following parameters were taken: the magnetic moment on the Co atom, $m_{\mathrm{Co}}=1.62 \mu_{B} /$ atom; and the fcc-Co lattice constant, $a=3.545 \AA$. The calculation gives the saturation magnetization, $M_{s}=1349 \mathrm{emu} / \mathrm{cm}^{3}$; uniaxial anisotropy constant, $K_{1}=4.53 \times 10^{6} \mathrm{erg} / \mathrm{cm}^{3}$ (whence one gets $H_{0}=3358 \mathrm{Oe}$ ), and exchange stiffness constant, $A=2.8 \times 10^{-6} \mathrm{erg} / \mathrm{cm}$ (the experimental value for nanocrystalline Co samples, according to Ref. [46]). Then for the ferromagnetic exchange length we get $L_{e x}^{0}=78.6 \AA$. The calculated particle size distribution is shown in Figure 9.

The temperature dependence of the residual magnetization provides another opportunity to calculate the particle size in

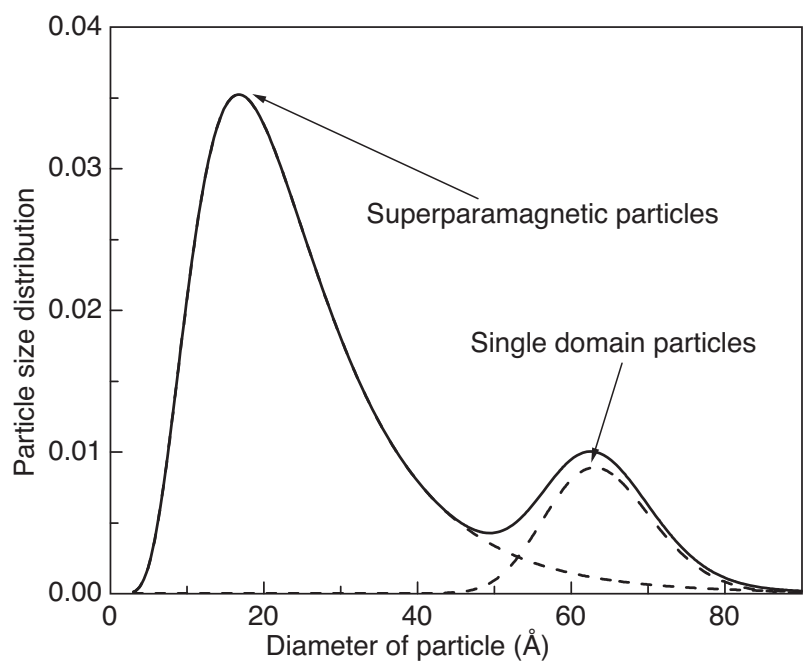

Figure 9

Particle size distribution of fine Co particles evaluated from the hysteresis loop shown in Figure 5 [40]. the catalysts containing single-domain and superparamagnetic particles. In this case, the particle size can be evaluated quantitatively. It is known that the upper critical size of single-domain particles is only weakly dependent on temperature, at least in the temperature range of 20 to $100{ }^{\circ} \mathrm{C}$ [47]. Using Equation (20), the $\gamma$ value was measured at 20 and $100{ }^{\circ} \mathrm{C}$ and assuming log-normal particle size distribution $[23,48]$ one can solve numerically and yield the distribution parameters: $\mu$ (average value) and $\sigma$ (mean-square deviation). $\mu$ and $\sigma$ can be calculated as follows:

$$
\begin{aligned}
& \bar{V}=\exp \left(\mu+\sigma^{2} / 2\right), \\
& \overline{(V-\bar{V})^{2}}=\exp \left(2 \mu+2 \sigma^{2}\right)-\exp \left(2 \mu+\sigma^{2}\right) .
\end{aligned}
$$

$V(T)$ is the critical volume of a superparamagnetic particle at a temperature $T$.

\section{MAGNETISM OF SMALL PARTICLES AND ADSORPTION}

All magnetic properties which are discussed above refer to bulk ferromagnetics. It is, however, obvious that decreasing particle size would result in a higher fraction of surface atoms which have a lower metal-metal coordination number. These surface atoms can adsorb molecules from the gaseous phase. Upon chemisorption the d-orbitals of surface atoms would be involved in chemical bonding with the adsorbate and thus, they would be excluded from magnetic exchange interaction. In fact, it appears that after adsorption and chemical bonding, the contribution of surface atoms to the overall magnetic properties of ferromagnetic or superparamagnetic particles is strongly affected. This suggests that the impact of adsorption on magnetization should be taken into account when studying the magnetic properties of small and especially nano-sized ferromagnetic particles.

The effect of adsorption on magnetization was observed very clearly with nickel catalysts. The dependences of magnetization on hydrogen coverage, which are also called "magnetic isotherms", were measured for these catalysts. Linear and reversible magnetic isotherms were observed with nickel-supported catalysts. The slope of the magnetic isotherms is approximately $1.4 \mu_{B}$. The atomic nickel magnetic moment is $0.6 \mu_{B}$, and hence $\alpha_{\mathrm{H}_{2}} \approx 2 \mu_{\mathrm{Ni}}$. This suggests that at dissociative adsorption of hydrogen on nickel, one hydrogen molecule eliminates approximately two nickel atoms from the magnetic interaction. In a comparative study of $\mathrm{H}_{2}$ and $\mathrm{O}_{2}$ adsorption on $\mathrm{NiCu}$ alloys [49], it was shown that, contrary to $\mathrm{O}_{2}, \mathrm{H}_{2}$ does not induce a demetallization of the surface atom (i.e. there is no surface hydride formation); only a magnetic decoupling occurs upon $\mathrm{H}_{2}$ adsorption.

The number of surface atoms that are magnetically decoupled by the adsorption has been called the "magnetic bond number" by Selwood $[8,50]$. This notion seems to be particularly suitable for nickel catalysts. This concept was extended 


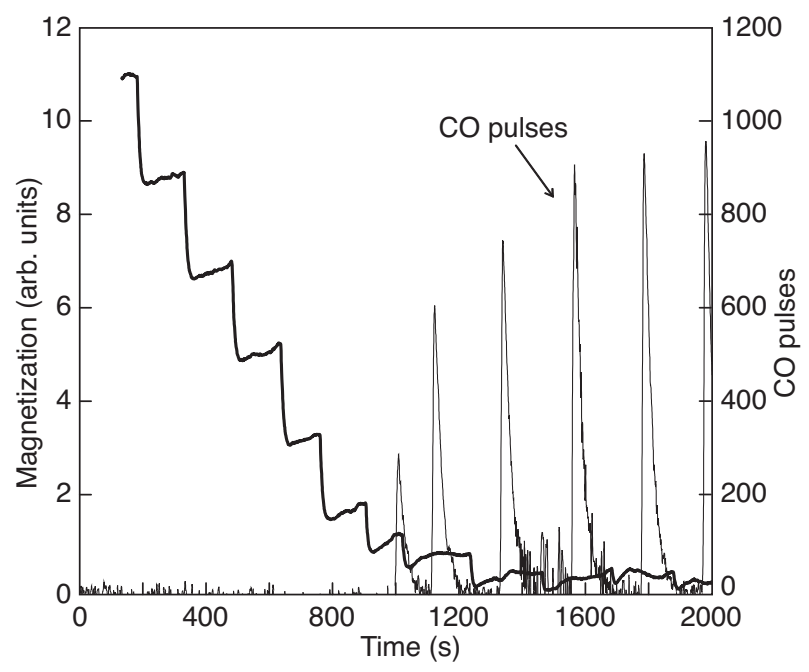

Figure 10

Influence of number of pulses of carbon monoxide on the magnetization of $40 \mathrm{wt} . \% \mathrm{Ni} / \mathrm{SiO}_{2}$ at $T=300 \mathrm{~K}$.

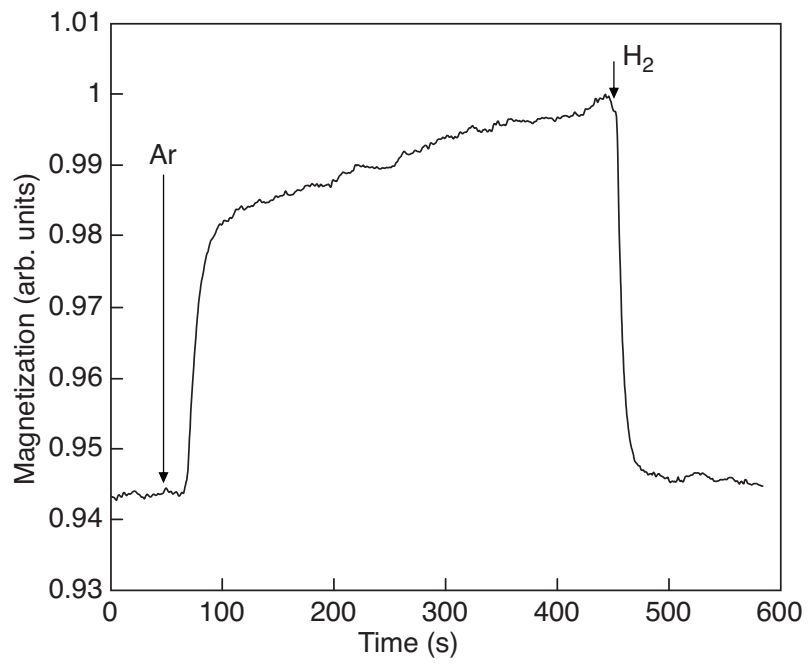

Figure 11

Temporal dependence of magnetization on time after switching from hydrogen to argon flow and vice versa for $\mathrm{Ni} / \mathrm{Cr}_{2} \mathrm{O}_{3}$ at $T=400 \mathrm{~K}$. to a series of molecules, giving the structure of the corresponding adsorbed species [51] and validated by comparing IR and magnetic results of $\mathrm{CO}$ adsorption on $\mathrm{NiCu}$ alloys [52]. Figure 10 shows magnetization which was measured using a vibrating sample magnetometer, as a function of the number of pulses of carbon monoxide into the argon flow passing through the $40 \mathrm{wt} . \% \mathrm{Ni} / \mathrm{SiO}_{2}$ catalyst at $T=300 \mathrm{~K}$. The pulses were generated by a 6-way valve and the chemical composition of the gaseous phase was measured on-line by an IR detector. After each pulse a drop of magnetization was first observed and then the magnetization was slightly increased. Apparently, this was due to the partial desorption of carbon monoxide. With oxygen adsorption on $\mathrm{Ni}$ or $\mathrm{Co}$ at $283 \mathrm{~K}$ the catalyst is likely to undergo oxidation. The relevant phenomena will be discussed in more detail below.

Figure 11 shows variation in relative magnetization of the $\mathrm{Ni} / \mathrm{Cr}_{2} \mathrm{O}_{3}$ catalyst when the flow of hydrogen over the catalyst was switched to a flow of argon at $T=400 \mathrm{~K}$ and vice versa. The observed increase in magnetization after switching from hydrogen to argon can be primarily attributed to the hydrogen desorption process. The subsequent switch from Ar to hydrogen leads to a rapid decline in magnetization to its level previously observed in the flow of hydrogen. This observation indicates that hydrogen and other chemisorbing gases have to be desorbed from the reduced catalysts prior to doing magnetic measurements when the extent of reduction or particle size are evaluated.

The relationship between magnetization and hydrogen coverage is even more complex for cobalt catalysts. If with nickel the dependence of magnetization on hydrogen coverage is not much affected by temperature, with cobalt catalysts $\alpha_{\mathrm{H} 2}$ increases with temperature. This seems to indicate that hydrogen adsorption is an activated process on cobalt catalysts, as was previously suggested by Bartholomew [5354]. Decrease in magnetic moment upon hydrogen adsorption on cobalt normalized by the number of cobalt surface atoms is $0.54 \pm 0.06 \mu_{B}$ at $T=300 \mathrm{~K}$ which yields $\alpha_{\mathrm{H}_{2}} \approx 1$ [55]. In a more detailed magnetic study, two types of $\mathrm{H}_{2}$ chemisorption were identified on Co, corresponding to molecular adsorption at room temperature $\left(\alpha_{\mathrm{H}_{2}} \approx 0.3 \mu_{B}\right)$ and dissociative adsorption at $200^{\circ} \mathrm{C}\left(\alpha_{\mathrm{H}_{2}} \approx 0.7 \mu_{B}\right)$ [56]. These $\alpha_{\mathrm{H}_{2}}$ values are much lower than those expected from the magnetic atomic moment of Co $\left(1.6 \mu_{B}\right)$, if surface atoms, as in the case of $\mathrm{Ni}$, have lost the magnetic contribution upon adsorption. This suggests that hydrogen does not completely cover the cobalt metallic surface, as is the case of nickel under similar conditions. Thus, $\mathrm{H}_{2}$ adsorption is not a convenient method to measure $\mathrm{Co}$ dispersion. This reinforces interest to magnetic granulometry for the characterization of Co-based Fischer-Tropsch catalysts.

Hydrogen adsorption on ultrafine iron does not modify, within the experimental error, its magnetization $\left(\alpha_{\mathrm{H}_{2}} \approx 0 \mu_{B}\right)$ [57].

It appears that $\alpha_{\mathrm{H}_{2}}$ decreases along with the sequence $\mathrm{Ni}$, $\mathrm{Co}, \mathrm{Fe}$. This has been related to the different electronic structures of the 3 metals, from "hard" ferromagnetic Ni (Fermi level crossing only the $d \downarrow$ sub-band) to "soft" Fe (Fermi level crossing both the $\mathrm{d} \downarrow$ and $\mathrm{d} \downarrow$ sub-bands). $\mathrm{H}_{2}$ adsorption 
modifies the Fermi level state density, generating a perturbation that is restricted to one sub-band $(\mathrm{Ni})$, leading to a strong perturbation, or is shared by the two sub-bands $(\mathrm{Fe})$, without global magnetic change. Co is an intermediate case [58].

\section{TOPOCHEMICAL REACTIONS IN IRON FISCHER-TROPSCH CATALYSTS}

Topochemical reactions often accompany Fischer-Tropsch synthesis. For example, in the hydrogenation of carbon monoxide on cobalt-supported catalysts, it was suggested that cobalt could be partially oxidized by water, especially at higher carbon monoxide conversions. Carburization is usually observed during Fischer-Tropsch synthesis on iron catalysts. Passivation of cobalt catalysts usually represents the formation of oxide layer on the surface of metal particles. The topochemical reactions which proceed during catalyst preparations, pretreatments and catalytic reactions have several specificities. In particular, little information is available about the dependence of thermodynamics and kinetics of topochemical reactions on the particle size of ferromagnetics in the range of $10-100 \mathrm{~nm}$.

Interaction between the supported metal or metal oxide and the support can also dramatically affect the catalyst activity and selectivity. With sub-ferrous metals, this interaction results in the changes in magnetization. This suggests that these processes can be investigated using magnetic methods. Combining the traditional temperature-programed reduction (TPR) with continuous measurements of magnetization has provided new insights into the mechanisms and kinetics of topochemical reactions proceeding during reduction, oxidation and different pretreatments of FischerTropsch catalysts. The section below reviews the data obtained for iron catalysts.

\subsection{Kinetics of Reduction of Iron Oxides}

Although the reduction of bulk metal oxides has been addressed in a very large number of works, the mechanism of reduction of small particles of metal oxides has been little studied. High reactivity of supported nano-oxides on the one hand, and competition between reduction and reaction of supported oxides with the support, on the other hand, makes this task particularly difficult. Figure 12 shows the dependence of magnetization on temperature, in other words, the thermomagnetic curve (TMC), obtained during temperatureprogramed heating of a $\mathrm{Fe}_{2} \mathrm{O}_{3} / \mathrm{SiO}_{2}(12 \mathrm{wt} . \% \mathrm{Fe}$ on KSK-2 silica) catalyst in a flow of hydrogen [59]. The $T_{1}, T_{2}, T_{3}$ temperatures, which correspond to the A, B, C points in Figure 12 , depend on the temperature ramping rate. Thus, the $X$ axis does not display the specific temperatures, but only the Curie temperature of iron (1043 K). The dotted lines correspond to TMC obtained during cooling down the sample from a given

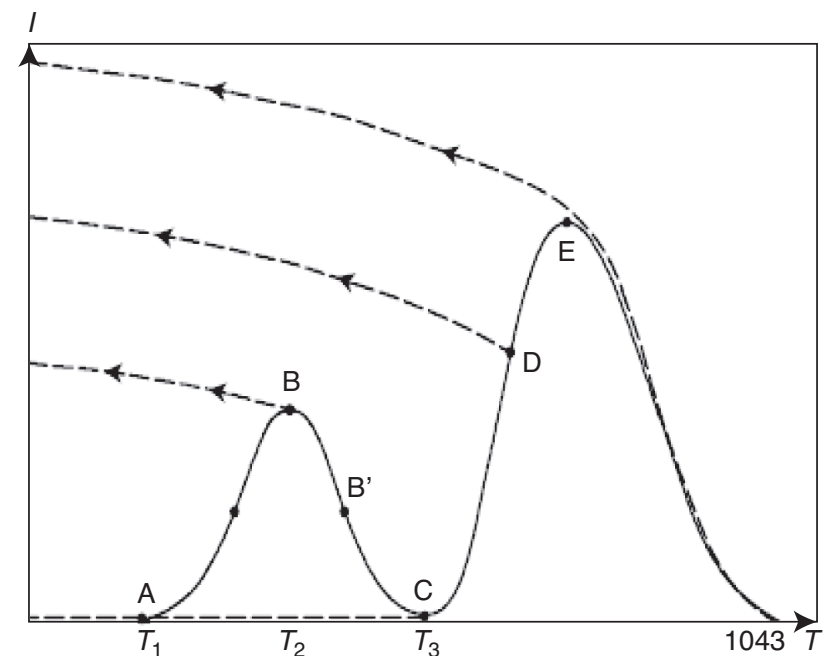

Figure 12

Dependence of magnetization on temperature during the reduction of $\mathrm{Fe}_{2} \mathrm{O}_{3} / \mathrm{SiO}_{2}$ with hydrogen.

to room temperature. Increase in the temperature ramping rate leads to a shift in the TMC towards higher temperatures, but upon reaching $1043 \mathrm{~K}$ the magnetization always drops to zero. This suggests that at the temperature ramping rates (up to $1.5 \mathrm{~K} / \mathrm{s}$ ), the sample has enough time to attain a thermal equilibrium with the registering thermocouples. The applied technique allows one either to stop the programmable heating or sharply cooling sample, or continue the experiment in the isothermal regime. It turned out that the catalyst, which was cooled down after attaining the $T_{2}$ temperature, regardless of ramping rate represents $\mathrm{Fe}_{3} \mathrm{O}_{4} / \mathrm{SiO}_{2}$. This was confirmed by measuring the Curie temperature of this sample, by XRD analysis and Mossbauer spectroscopy. The sample, which was heated to $T_{3}$ and then cooled down to room temperature, had no magnetization. XRD and Mossbauer spectroscopy showed that in the catalyst obtained from the cooling from $T_{3}$ to room temperature all iron was in the form of vustite $(\mathrm{FeO})$ [60]. When the catalyst is heated above the $T_{3}$ temperature, the increase in magnetization is due to the reduction of $\mathrm{FeO}$ to $\alpha-F e$. $\alpha$-Fe was detected in these conditions by XRD.

The total saturation magnetic moment, $M^{s}$, experimentally measured by the magnetometer due to the presence of $n$ magnetic phases, can be expressed as follows:

$$
\begin{aligned}
& M^{s}(T)=\sum_{i} M_{i}^{s}(T) \\
& M_{i}^{s}(T)=\sigma_{i}^{s}(T) \cdot m_{i}
\end{aligned}
$$


where $\sigma_{i}^{s}(T)$ is the specific saturation magnetization of the $i$-th phase at $T$ temperature; $m_{i}$ is the mass of the $i$-th phase with

$$
\lim _{T \rightarrow T(\theta)} \sigma_{i}^{s}(T)=0
$$

where $T(\theta)$ - is the Curie temperature of the $i$-th phase. If the function $\sigma_{i}^{s}(T)$ is known for each phase, then $m_{i}$ can be obtained from Equations (23-25) using the experimental data $M^{s}(T)$. Note that the following method of determining $m_{i}$ remains valid provided the contribution to the magnetization of superparamagnetic particles can be neglected. In Reference [60] a magnetic hysteresis in the field dependence curve was observed for all the samples. It can be suggested that the fraction of particles smaller than $8 \mathrm{~nm}$ was minor.

The specific saturation magnetization $\sigma_{i}^{s}(T)$ of magnetite and iron was calculated from the experimentally measured temperature dependences of the saturation magnetic moment of commercially available $\mathrm{Fe}_{3} \mathrm{O}_{4}$ and $\alpha-\mathrm{Fe}$ (high purity grade). The thermomagnetic curves $M^{s}(T)$ were obtained by heating the sample in the flow of pure helium to avoid sample oxidation during the measurements. The empirical dependencies of specific saturation magnetization $\sigma_{i}^{s}(T)$ can be reasonably well described by polynomials $P^{k}(T)$, where $k=7$. Substitution of the empirical relationships into the system of Equations (23-25) allows determination of $m_{i}$ at any point of temperature-programed reduction with simultaneous recording of the magnetization. It can be assumed that the measured $M^{s}$ is proportional to the $m$ mass of the reference samples of magnetite and iron [12].

The above method allows the measurement of the concentration of magnetic phases anywhere on the thermomagnetic curve. The characteristic points of the spectrum are $T_{\max }$ and $T_{\min }$ (in Fig. 12, points B and C, respectively). A total magnetization of the sample was measured at the points $\mathrm{C}\left(T_{\min }\right)$ and B $\left(T_{\max }\right)$ after heating it to the appropriate temperature and further cooling to room temperature. The observed magnetic moment is due to the presence of either $\mathrm{Fe}_{3} \mathrm{O}_{4}$ or $\mathrm{Fe}$ or both compounds. The presence of these phases was confirmed by XRD. In addition, at the magnetization minimum (point C) XRD detected the presence of $\mathrm{FeO}$. The method described above allows determination anywhere the value of $m$ and the fractions of $\mathrm{Fe}_{3} \mathrm{O}_{4}$ and $\mathrm{Fe}$ at $T_{\max }$ and $T_{\min }$. The calculation showed that the concentration of magnetite did not depend on the temperature ramping rate and is equal to $85 \%$ at $V_{\mathrm{H}_{2}}=60 \mathrm{ml} / \mathrm{min}$. At high ramping rates, magnetite concentration substantially depends on the flow rate of hydrogen. When the flow is less than $40 \mathrm{ml} / \mathrm{min}$, a sharp decrease in the concentration of magnetite is observed. This decrease is attributed to the formation of $\mathrm{FeO}$.

Isothermal heating at a given temperature allows more detailed investigation of the selected reduction steps $\mathrm{Fe}_{2} \mathrm{O}_{3} \rightarrow \mathrm{Fe}_{3} \mathrm{O}_{4} \rightarrow \mathrm{FeO} \rightarrow \mathrm{Fe}$ (Fig. 12) [61]. Using the dependence of the temperature of emergence of ferro- and ferrimagnetic phases on the ramping rate, the kinetics of formation of different phases can be followed at different temperatures and thus, the apparent activation energies can be determined. The kinetic curves obtained at different temperatures were analyzed assuming uniformity of the reaction space.

It appears that the kinetics of $\mathrm{Fe}_{2} \mathrm{O}_{3} / \mathrm{SiO}_{2} \rightarrow \mathrm{Fe}_{3} \mathrm{O}_{4} / \mathrm{SiO}_{2}$ transformation at the temperature range from 573 to $615 \mathrm{~K}$ is well described by Erofeev-Avrami equation:

$$
[-\ln (1-\alpha)]^{1 / 2}=k t
$$

where $\alpha$ is the product fraction and $k$ is the kinetic constant.

The kinetics of isothermal reduction of $\mathrm{Fe}_{3} \mathrm{O}_{4} / \mathrm{SiO}_{2}$ to $\mathrm{FeO} / \mathrm{SiO}_{2}$ exhibits a high initial rate and is described by the model of a shrinking sphere coupled with diffusion (Yander equation):

$$
\left[1-(1-\alpha)^{1 / 3}\right]^{2}=k t
$$

The same model can also be used to describe the transformation $\mathrm{FeO} / \mathrm{SiO}_{2} \rightarrow \mathrm{Fe} / \mathrm{SiO}_{2}$.

The technique of continuous measurement of magnetization during reduction has been very useful for studying the effect of the reduction promoters such as $\mathrm{Pt}$, or $\mathrm{Cu}$ [62]. Temperature dependence of magnetization during the reduction of $\mathrm{Fe}_{2} \mathrm{O}_{3} / \mathrm{SiO}_{2}$ and $\mathrm{Pt} / \mathrm{Fe}_{2} \mathrm{O}_{3} / \mathrm{SiO}_{2}$ catalysts in hydrogen shows that $\mathrm{Pt}$ promotion lowers the temperature of iron reduction.

\subsection{Kinetics of Iron Carburization in Carbon Monoxide Hydrogenation}

Several iron carbides have been described in the literature: $\mathrm{FeC}$ carbide, hexagonal $\varepsilon-\mathrm{Fe}_{2} \mathrm{C}$ (Curie temperature $T_{\theta}=$ $653 \pm 10 \mathrm{~K})$, pseudo-hexagonal $\varepsilon^{\prime}-\mathrm{Fe}_{2.2} \mathrm{C}\left(T_{\theta}=723 \pm 10 \mathrm{~K}\right)$, monoclinic Hägg $\chi-\mathrm{Fe}_{5} \mathrm{C}_{2}$ carbide $\left(T_{\theta}=478-529 \mathrm{~K}\right.$ varies according to different sources) and orthorhombic $\theta-\mathrm{Fe}_{3} \mathrm{C}$ cementite $\left(T_{\theta}=481 \pm 3 \mathrm{~K}\right)$ [63-66]. Each of these carbides can be detected during Fischer-Tropsch synthesis on iron catalysts [67]. The carbide composition depends on the $\mathrm{H}_{2} / \mathrm{CO}$ ratio, size of iron particles, extent of iron reduction and temperature.

It appears that in the conditions of Fischer-Tropsch synthesis iron carburization involves hydrogen. Matsumoto and Bennett [68] showed that in the mixture of $\mathrm{H}_{2}$ and $\mathrm{CO}$ iron can be carburized more readily than in $\mathrm{CO} / \mathrm{Ar}$. In the latter case carburization proceeds much more slowly and leads to another phase composition of carburization products. The authors suggest the following reaction for carburization in syngas: $4 \mathrm{CO}+6 \mathrm{Fe}+2 \mathrm{H}_{2}=2 \mathrm{H}_{2} \mathrm{O}+\mathrm{CO}_{2}+3 \mathrm{Fe}_{2} \mathrm{C}$.

The $\varepsilon$ '-carbide usually occurs during Fischer-Tropsch synthesis on iron catalysts promoted with $\mathrm{K}_{2} \mathrm{O}, \mathrm{Cu}$ and $\mathrm{Si}$ [65]. It is thermally instable in the absence of promoters and at $T>623 \mathrm{~K}$ it readily transforms into Hägg carbide. As the carburization advances, a mixture of $\varepsilon^{\prime}$-carbide and Hägg $\chi-\mathrm{Fe}_{5} \mathrm{C}_{2}$ carbide appears, at the end of carburization only $\chi$-carbide has been detected [66]. 
Formation of cementite during Fischer-Tropsch synthesis is typically an outcome of its thermal stability and easy decomposition of Hägg carbide in the excess of iron. It has been shown [65] that stability of iron carbides increases in the following sequence: $\varepsilon^{\prime}-\mathrm{Fe}_{2.2} \mathrm{C}<\varepsilon-\mathrm{Fe}_{2} \mathrm{C}<\chi-\mathrm{Fe}_{5} \mathrm{C}_{2}<\theta-\mathrm{Fe}_{3} \mathrm{C}$. The carbides transform from one form into another with increase in temperature. Loktev et al. observed [69] that $\varepsilon$ - and $\varepsilon^{\prime}$-carbides occured at $388 \mathrm{~K}$, at $423-458 \mathrm{~K}$ only $\varepsilon$-carbide was detected, at 493-673 K ع-carbide transforms into Hägg carbide, and at $723 \mathrm{~K}$ the cementite phase was obtained.

Among different iron carbides, the identification of $\varepsilon^{\prime}-\mathrm{Fe}_{2.2} \mathrm{C}$ and $\varepsilon-\mathrm{Fe}_{2} \mathrm{C}$ carbides is particularly difficult [70, $71]$. It is not always very clear whether $\varepsilon$ ' or $\varepsilon$-carbide can be considered as a primary product of iron carburization [66]. The data about lattice parameters of $\varepsilon$ '- and $\varepsilon$-iron carbides vary considerably according to different authors. This could lead to their incorrect identification from XRD data. The magnetic measurements can provide additional information about the composition of carbide phases, because of difference in their Curie temperatures.

Investigation of carburization kinetics using the in situ magnetic method has proven to provide important information. In the conditions when only $\varepsilon$ '- and $\chi$-carbides occur, the fractions of these carbides can be deduced by the solution of linear equations with two unknown parameters:

$$
X_{1} M\left(\varepsilon^{\prime}\right) \sigma\left(\varepsilon^{\prime}\right)+X_{2} M(\chi) \sigma(\chi)-I_{\mathrm{c}}=0
$$

$\sigma(\mathrm{Fe})\left\{\left(M\left(\varepsilon^{\prime}\right)-12\right) X_{1}+(M(\chi)-12) X_{2}\right\}-I_{\mathrm{Fe}}=0$

where $\sigma(i)$ is the specific magnetization $i$-th phase at room temperature, $X_{1}$ and $X_{2}$ are, respectively, the number of moles of $\varepsilon^{\prime}-$ and $\chi$-carbides, $M\left(\varepsilon^{\prime}\right)$ and $M(\chi)$ are their molecular weights, and $I_{\mathrm{C}}$ and $I_{\mathrm{Fe}}$ are the measured magnetizations.

During carburization the overall magnetization of the sample decreases because $\sigma(\mathrm{Fe})>\Sigma \sigma(i)$ over a whole temperature range. This allows the extent of iron carburization to be determined using the following expression:

$$
\alpha(t)=\frac{I_{o}^{T}-I_{c}^{T}(t)}{I_{o}^{T}-I_{c}^{T}(\infty)}
$$

where $\alpha(t)$ is the carburization conversion at time $t, I_{i}$ is sample magnetization at $T$ temperature, and $i$ means the following: $i=0$ for the initial sample; $i=c$ for a carburized sample at time $t$ and after completing the carburization $I_{\mathrm{c}}^{T}(\infty)$. The kinetics of carburization can be followed using continuous measurement of magnetization [72]. In addition, the measurement of the initial and final magnetization allows the composition of the carbide phases to be quantitatively determined. This is possible because the carbide content is stoichiometrically related to the mass of iron in the sample before the carburization. It should be noted that application of this method imposes some restrictions on phase composition. Thus, the presence of magnetite makes the application of Equation (29) incorrect, because in this case the magnetite contributes to the total magnetization.
The specific rate of carburization can be determined by the equation:

$$
W=\frac{n}{s} \cdot \frac{d \alpha}{d t}
$$

where $n$ is the number of iron moles, and $s$ is the specific area of iron.

The conventional phenomenological theory of chemical kinetics involving a gas and a solid describes the situation which arises after the nuclei of the solid phase product are formed, and when heterogeneous inclusions appear within the solid. This is the so-called "pre-nuclear" period, which determines nucleus generation and thus further progress of the reaction [49]. It turns out that at very low conversions $(\alpha<0.03)$ the dependence of the carburization rate on the reaction time has a characteristic minimum. The sharp decline in the carburization rate in the initial period is due to the need to overcome some resistance because of the formation of nuclei solid products. This effect is most pronounced at temperatures below $523 \mathrm{~K}$. It has been shown [73-74] that the number of nuclei of the carbide phase is a function of time:

$$
N=z_{0} S\left[1-\exp \left(-k_{2} t\right)\right]
$$

where $z_{\mathrm{o}}$ is the number of potential sites of nucleation, $S$ is the surface area and $k_{2}$ is the rate constant of nuclei formation. The dependence of conversion on time is described by the Avrami- Erofeev equation:

$$
N=z_{\mathrm{o}} S\left[1-\exp \left(-k_{2} t\right)\right]
$$

where $k_{1}{ }^{\prime}=k_{1} / z_{0} S / n$. Processing experimental data using Equation (31) yields the values of $k_{1}$ and $k_{2}$ through minimizing the root-mean-square deviation.

Obviously, the method of continuous measurement of magnetization can be applied to studying any other topochemical process which involves changes in magnetization. Naturally, the temperature of the experiment should not exceed the Curie temperature of ferromagnetic species.

\section{CHARACTERIZATION OF COBALT CATALYSTS DURING DIFFERENT PRETREATMENTS AND THE FISCHER-TROPSCH REACTION}

Because of their stability, higher per pass conversion and high hydrocarbon productivity, cobalt catalysts represent the optimal choice for synthesis of long-chain hydrocarbons in Fischer-Tropsch synthesis. The Fischer-Tropsch reaction proceeds on cobalt metal particles supported by oxide supports $\left(\mathrm{Al}_{2} \mathrm{O}_{3}, \mathrm{SiO}_{2}, \mathrm{TiO}_{2}\right.$, etc.). Information about the cobalt metal species is therefore crucial for the design of these catalysts. Only metallic cobalt has ferromagnetic properties. This makes data interpretation much easier than for iron catalysts. Both $\mathrm{Co}_{3} \mathrm{O}_{4}$ and $\mathrm{CoO}$ are antiferromagnetic at lower temperatures. At the Néel temperature $\left(30 \mathrm{~K}\right.$ for $\mathrm{Co}_{3} \mathrm{O}_{4}$ [75], $288 \mathrm{~K}$ for $\mathrm{CoO}$ [76]) they undergo antiferromagnetic-paramagnetic 

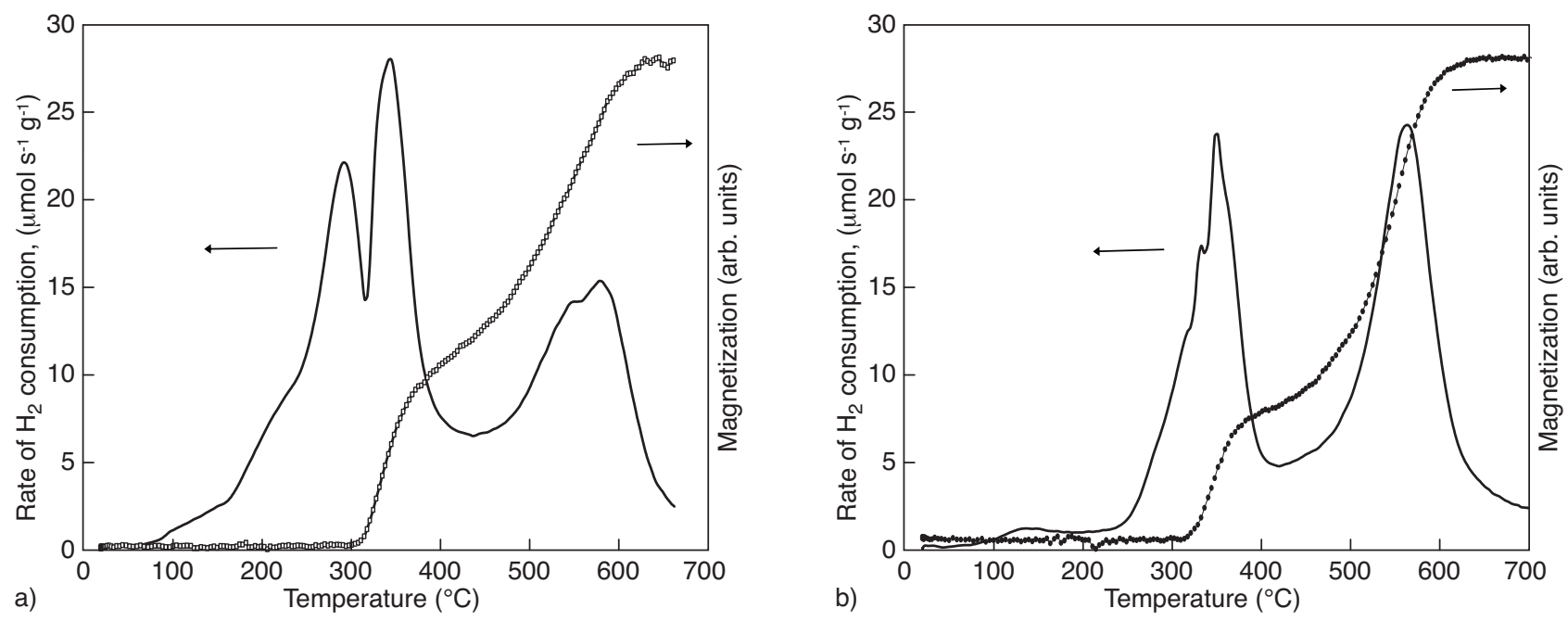

Figure 13

Combined TPR and magnetization profiles during the reduction of $15 \% \mathrm{Co} / \mathrm{ZrO}_{2}+6 \% \mathrm{Y}_{2} \mathrm{O}_{3}$ (I) $T_{\text {calc }}=300^{\circ} \mathrm{C}$ a) and $600^{\circ} \mathrm{C} \mathrm{b}$ ), $t_{\text {calc }}-0.5 \mathrm{~h}$.

transition. At ambient and higher temperatures, both $\mathrm{Co}_{3} \mathrm{O}_{4}$ and $\mathrm{CoO}$ exhibit paramagnetic behavior. This leads to only very small magnetization of the oxidized cobalt catalysts in the magnetic field. Our estimations suggest that the contribution of cobalt oxides to the overall magnetization is much lower than $5 \%$. Thus, for cobalt-containing catalysts the magnetic method is almost selectively sensitive to the presence of cobalt metallic species.

The magnetic measurements for cobalt catalysts can be conducted either in situ or ex situ. The in situ experiments involve measuring catalyst magnetization during different pretreatments and catalytic reaction. Cobalt has a high Curie temperature $(\approx 1400 \mathrm{~K})$ and hence cobalt reduction in most cases can be investigated in situ. A combination of the conventional methods of catalyst investigation such as temperature-programed reduction (TPR) with a continuous measurement of magnetization has proved to be very fruitful. The ex situ experiments address characterization of catalysts which were exposed to the reacting medium and then transferred to the magnetometer. In several cases this transfer can be done without exposure to air.

The magnetic method can provide three sorts of information about cobalt FT catalysts. First, the extent of reduction can be evaluated. The measurement of the concentration of the cobalt metal phase can often be done in situ in transient conditions. Secondly, the magnetic method can provide important information about oxidation of cobalt nanoparticles. Thirdly, the sizes of cobalt metal particles can be measured from the magnetic data.

\subsection{Reducibility Measurements}

Reduction of cobalt species can be followed in situ using the magnetic method coupled with conventional TPR. Since the magnetic method is very sensitive to the presence of ferromagnetic phases, the formation of cobalt metal particles can be detected at relatively low concentrations, as was done for example, in $\mathrm{La}(\mathrm{Co}, \mathrm{Fe}) \mathrm{O}_{3}$ perovskites $[77,78]$.

In contrast to conventional TPR, which operates with diluted hydrogen, the magnetic measurements can be done in pure hydrogen. This leads to more reliable data about cobalt reducibility than those obtained from conventional TPR. It was shown [79] that diluted hydrogen in TPR experiments could lead to significantly lower extents of reduction than those normally attained in pure hydrogen. The magnetic method can also detect the temperature of emergence of the cobalt metal phase. This information is essential for prediction and description of catalytic performance of cobalt catalysts in Fischer-Tropsch synthesis.

Figure 13 shows TPR profiles of $15 \% \mathrm{Co} / \mathrm{ZrO}_{2}+6 \%$ $\mathrm{Y}_{2} \mathrm{O}_{3}$ catalysts, calcined prior to reduction at 300 and $600^{\circ} \mathrm{C}$ for $0.5 \mathrm{~h}$ [80]. The same figure also displays the temperature dependence of magnetization during TPR measurements for the same catalysts. The low temperature TPR peak is not accompanied by an increase in magnetization. This suggests that this peak can be attributed to partial reduction of cobalt oxide which does not result in emergence of the ferromagnetic phase, probably $\mathrm{Co}_{3} \mathrm{O}_{4} \rightarrow \mathrm{CoO}$ transition. The TPR peak observed at higher temperatures is accompanied by increase in magnetization. And thus, it could probably be 


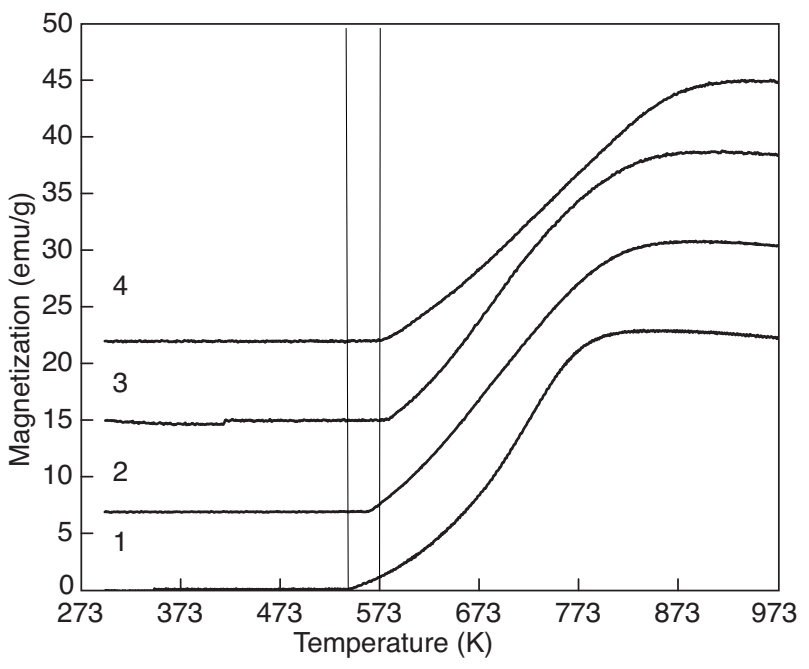

Figure 14

Magnetization versus temperature in pure hydrogen for monometallic cobalt alumina-supported catalysts calcined at (1) $473 \mathrm{~K}$, (2) $613 \mathrm{~K}$, (3) $673 \mathrm{~K}$, (4) $773 \mathrm{~K}$ (ramping rate $28.2 \mathrm{~K} / \mathrm{min}$ ). Reprinted from [112] with permission from Elsevier.

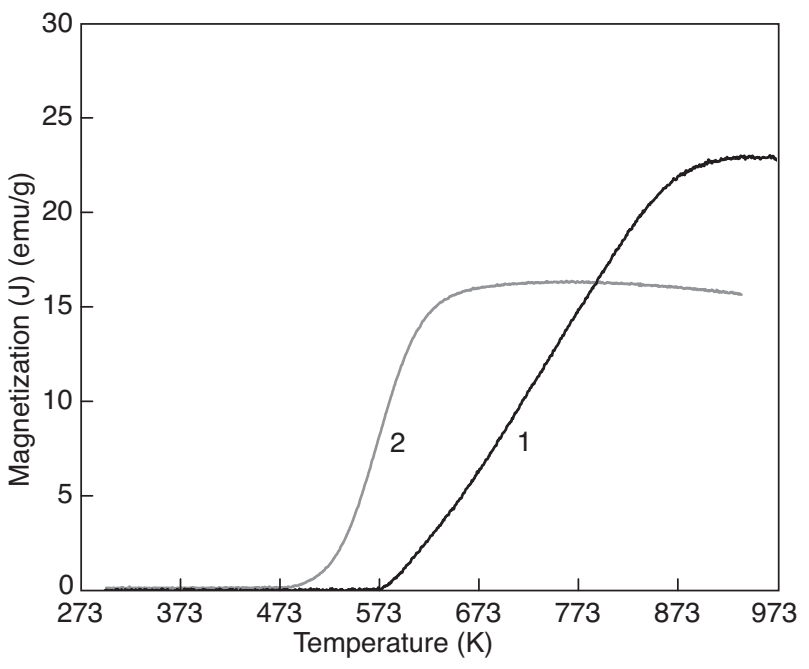

Figure 15

Magnetization versus temperature in pure hydrogen for monometallic (1) and (2) platinum promoted (0.1 wt.\% Pt) cobalt alumina-supported catalysts (catalyst calcination temperature is $773 \mathrm{~K}$, ramping rate during reduction $28.2 \mathrm{~K} / \mathrm{min})$. attributed to the $\mathrm{CoO} \rightarrow \mathrm{Co}$ reduction step. High catalyst calcination temperature leads to the decrease in intensity of the low temperature TPR peak and to its disappearance for the catalyst precalcined at $600^{\circ} \mathrm{C}$. This is probably attributed to lower stability of supported $\mathrm{Co}_{3} \mathrm{O}_{4}$ at higher temperatures and its transformation into more stable $\mathrm{CoO}$. At $T>500^{\circ} \mathrm{C}$ the TPR profiles exhibit the third peak, which is accompanied by an increase in magnetization and thus corresponds to the emergence of the metal phase. This peak could be attributed to the reduction of a mixed, hardly reducible $\mathrm{Co}-\mathrm{Zr}$ oxide.

Figures 14 and 15 dispaly the in situ magnetic data for monometallic and Pt-promoted cobalt alumina-supported catalysts obtained in pure hydrogen. It appears [81] that the temperature of emergence of the cobalt metal phase in monometallic cobalt alumina-supported catalysts is a function of the catalyst calcination temperature. The cobalt metallic phase was detected starting from $547 \mathrm{~K}$ in the catalyst which was calcined at $473 \mathrm{~K}$, while in the catalysts precalcined at higher temperatures $(643,673$ and $773 \mathrm{~K})$, the cobalt metallic phase emerges at 570-581 K. Different results were obtained for silica-supported catalysts. In those catalysts it was found that cobalt reduction proceeded much more easy when the catalysts were calcined at moderately higher temperatures (673 K instead of $423 \mathrm{~K}$ [82]). These effects were interpreted in different interactions between the cobalt and support in alumina- and silica-supported catalysts. Promotion with noble metals ( $\mathrm{Pt}, \mathrm{Ru}$ and $\mathrm{Re})$ can also significantly facilitate cobalt reduction [79, 81, 83]. Figure 15 shows that cobalt metal particles in Pt-promoted catalysts can be detected by the magnetic method at $463-473 \mathrm{~K}$, while in monometallic cobalt catalysts the metallic particles were usually observed above $563 \mathrm{~K}$.

The magnetic method could also provide information about the mechanism of cobalt reduction. Figure 16 displays differential magnetization $(d J / d T)$ measured at different heating rates for Pt-promoted cobalt alumina-supported catalysts. The differential magnetization is proportional to the rate of formation of cobalt metal phases. Figure 16 shows that the position of the differential magnetization maxima is a function of the catalyst heating rate; the maximum of differential magnetization is situated at a lower temperature, when the catalyst is heated with a slower heating rate. This suggests that formation of cobalt metal phases is an activated process. The activation energy of formation of the cobalt metal phase can be calculated using the equation [84]:

$$
\frac{d\left(\ln \frac{\Phi}{T_{m}^{2}}\right)}{d\left(\frac{1}{T_{m}}\right)}=-\frac{E}{R}
$$

where $E$ is the activation energy, $R$ is the universal gas constant, $\Phi$ is the heating rate and $T_{m}$ is the temperature of the maximum of differential magnetization. In this method the activation energy is calculated from the slope in the plot of 


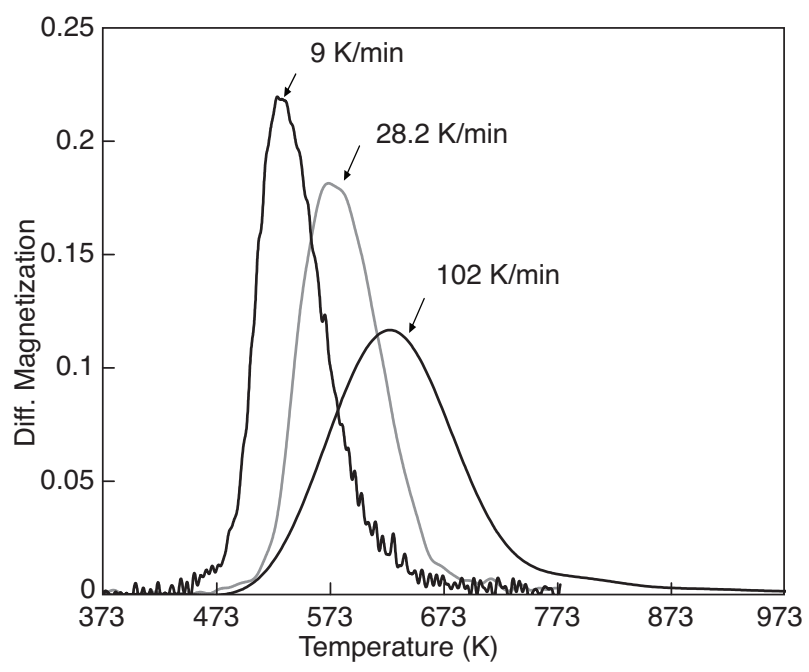

Figure 16

Influence of temperature rate on the differential magnetization of a cobalt Pt-promoted cobalt aluminasupported catalyst in pure hydrogen. Reprinted from [112] with permission from Elsevier.

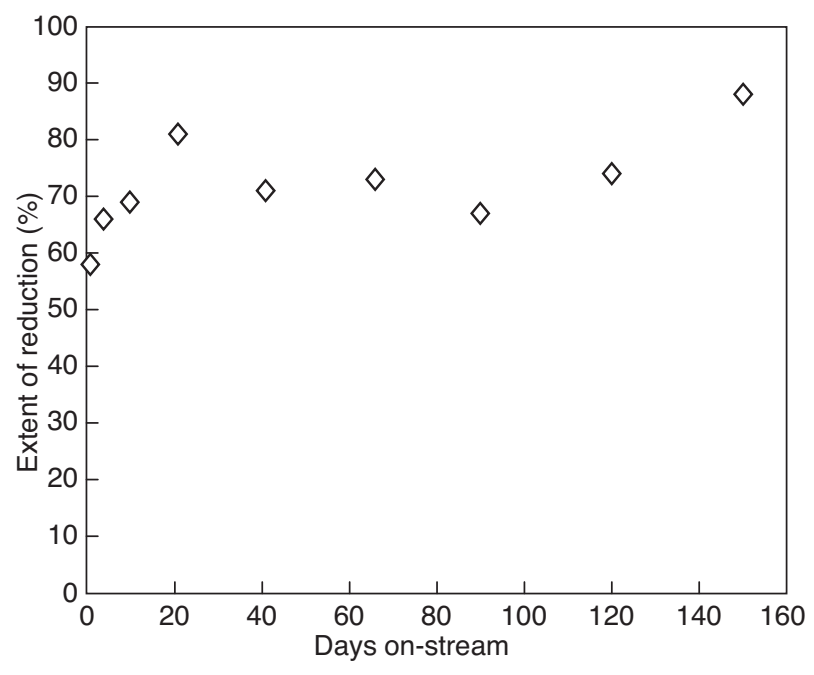

Figure 17

Extent of cobalt reduction in cobalt alumina-supported catalysts as a function of time on-stream in a slurry bubble column reactor. $\ln \left(\frac{\Phi}{T_{m}^{2}}\right)$ versus $\left(\frac{1}{T_{m}}\right)$. The activation energies of formation of cobalt metal phases for monometallic and Pt-promoted cobalt alumina-supported catalysts were, respectively, 130 and $60 \mathrm{~kJ} / \mathrm{mol}$ [81].

Other promoters of Co reduction have been studied. The selective production of higher alcohols (gasoline boosters) from syngas is a special case of Fischer-Tropsch synthesis developed by the IFP [85-86]. The process makes use of $\mathrm{Co} / \mathrm{Al}_{2} \mathrm{O}_{3}$ catalysts obtained via a specific coprecipitation method with $\mathrm{Cu}, \mathrm{Zn}$ and $\mathrm{Na}$ as promoters. It has been shown by a combined TPR/magnetic study that $\mathrm{Cu}$ favors $\mathrm{Co}$ reduction via two effects:

- $\mathrm{Cu}$ decreases the amount of Co ions located in the spinel $\mathrm{CoAl}_{2} \mathrm{O}_{4}$, a structure that is difficult to reduce

- metallic copper, produced at low reduction temperatures, may act as a catalyst for the Co reduction [87].

Unfortunately, in situ magnetic measurements are not always feasible in realistic Fischer-Tropsch reaction conditions, because of difficulties maintaining high pressures and temperatures in the experimental cell during magnetic measurements. In this case, however, the essential information about cobalt catalysts can be obtained using a "pseudo in situ" method [88]. Note that in the reactor, cobalt catalysts are usually coated with hydrocarbon wax produced by FischerTropsch synthesis. It is assumed that this wax can protect cobalt catalysts from reoxidation during their transfer from the reactor to the magnetometer and during the magnetization measurements. Van de Loosdrecht et al. [88] characterized wax-coated cobalt alumina-supported catalysts which were exposed to commercially relevant Fischer-Tropsch conditions $\left(503 \mathrm{~K}, 20\right.$ bar $\left(\mathrm{H}_{2}+\mathrm{CO}\right)$, conversion between 50 and $\left.70 \%\right)$ in a 100 barrel/day slurry bubble column reactor with a diameter of $0.9 \mathrm{~m}$. The extent of reduction was calculated from the value of saturation magnetization. Figure 17 shows the extent of cobalt reduction in the alumina-supported catalysts as a function of time on-stream. The extent of cobalt reduction does not seem to decrease with time on-stream. It is often postulated $[1,89,90]$ that reoxidation of small supported cobalt particles by water produced by Fischer-Tropsch synthesis is the principal reason for catalyst deactivation. The magnetic data [88] suggest however that reoxidation of cobalt metal particles in industrial Fischer-Tropsch reactors could be prevented by efficient control of water and hydrogen pressures.

The metallic stability of cobalt under Fischer-Tropsch conditions $\left(523 \mathrm{~K}, 50\right.$ bar $\left(2 \mathrm{H}_{2}+\mathrm{CO}\right)$, GHSV $\left.10^{4} \mathrm{~h}^{-1}\right)$, has also been related to the catalyst formulation [87]. In line with report [88], the magnetization of a $\mathrm{Co} / \mathrm{Al}_{2} \mathrm{O}_{3}$ catalyst, selective towards hydrocarbons, is unchanged during the reaction, the observed catalyst deactivation being related to carbon fouling (no bulk oxide or carbide formation). Contrarily, the $\mathrm{CuNaZn-promoted} \mathrm{Co} / \mathrm{Al}_{2} \mathrm{O}_{3}$, selective towards higher alcohols, shows, under similar reaction conditions, a loss of metallic cobalt that has been related to the formation of $\mathrm{Co}_{2} \mathrm{C}$ [87].

\subsection{Oxidation of Cobalt Nanoparticles}

Oxidation of small cobalt particles in Fischer-Tropsch catalysts is important from both practical and theoretical 
points of view. Practically, it is important to know the optimal conditions for passivation of reduced catalysts. In addition, it is essential to know the conditions when the active metal can be oxidized. Both of these phenomena require understanding the specificity of oxidation of small metal particles.

From the theoretical point of view, small metal nanoparticles can be considered as model systems to study the dependence of topochemical reactions on the particle size of ferromagnetics. The method of continuous in situ measurement of magnetization provides important information about their low temperature oxidation (from 280 to $500 \mathrm{~K}$ ).

During oxidation the magnetization decreases from the initial value which corresponds to the reduced sample, $I_{0}$, to some value, $I(t)$, which corresponds to time $t$. Assuming the number of cobalt metal particles to be constant, the magnetization, $I_{0}$, is proportional to $r^{3}$, where $r$ is the radius of an average Co particle. From geometric considerations it is easy to show that the oxide layer thickness can be defined as follows:

$$
\delta=r \cdot\left[1-\left(1.48 \cdot\left(\frac{I_{0}}{I(t)}-1\right)+1\right)^{-1 / 3}\right]
$$

where 1.48 is the ratio of $\mathrm{Co}$ and $\mathrm{CoO}$ densities.

It is known that the gradient of electric potential is very small when oxide films have considerable thickness. Consequently, the mass transfer only depends on the concentration gradients. In these circumstances the oxidation proceeds according to the parabolic law, which follows from the theory of Wagner [91]. In the case of thin oxide films, however, especially at low temperatures, when the diffusion of ions is hindered, the gradient of electric potential may play a major role. The kinetics of thin oxide film formation at low temperatures is consistent with the Cabrera-Mott theory [92]. The theory predicts the existence of a critical temperature. Below this temperature the film thickness reaches the limit, which can be several dozens of angstroms. After attaining this limit the film growth considerably slows down.

The thickness, $\delta$, of oxide film is a function of the temperature. This thickness can be determined from the equation:

$$
\delta=\frac{V e b}{\left(W-39 k_{B} T\right)}
$$

where $V$ is the electric potential in the oxide layer, $e$ is the electron charge, $b$ is the value approximately equal to a half of the interplanar distance of the oxide crystal lattice, $W$ is the work necessary to remove from the cation vacancy from the surface to the volume and $k_{B}$ is the Boltzmann constant. Equation (35) suggests that the thickness limit exists only at temperatures below $W / 39 k_{B}$.

Figure 18 shows the dependence of the thickness of oxide layer on time for the isothermal oxidation of a $10 \mathrm{wt} . \%$ $\mathrm{Co} / \mathrm{Al}_{2} \mathrm{O}_{3}$ catalyst at several temperatures. After the oxide film has attained some thickness, its growth is strongly affected by the temperature. This qualitatively corresponds to the oxidation involving the Cabrera-Mott model [92]. Oxidation in non-isothermal mode allows the production of TPO (temperature-programed oxidation) profiles, which reflect the dependence of the oxidation rate on temperature. The oxidation rate is determined by the rate of decrease in magnetization, thus the magnetization-TPO profiles in this case reflect only a drop in cobalt metal concentration, as opposed to the traditional method of TPO, which records the overall rate of oxygen absorption by the sample. Figure 19 displays magnetization-TPO profiles for the $10 \mathrm{wt} \%$ $\mathrm{Co} / \mathrm{ZrO}_{2}+6 \% \mathrm{Y}_{2} \mathrm{O}_{3}$ catalyst.

To explain the presence of several peaks in magnetizationTPO profiles which correspond to several maxima of oxidation rates, the fraction of superparamagnetic particles was measured at different stages of oxidation. The highest is the fraction of superparamagnetic particles, the smallest is the average size of cobalt particles in the catalyst. The measurements of the residual magnetization indicate a decline in the fraction of superparamagnetic particles after the first TPO peak has been attained. Thus, it follows that the first TPO peak is probably due to the oxidation of relatively small $\mathrm{Co}$ particles, while the second peak corresponds to the oxidation of larger metal particles.

The magnetization-TPO spectra can therefore provide the essential information about the metal particle size distribution. Note that it is rather difficult to extract this information from the conventional TPO method, because the TPO profiles are usually rather complex. A combination of TPO profiles with in situ measurements of magnetization provides new insights into metal particle size distribution in cobalt catalysts.

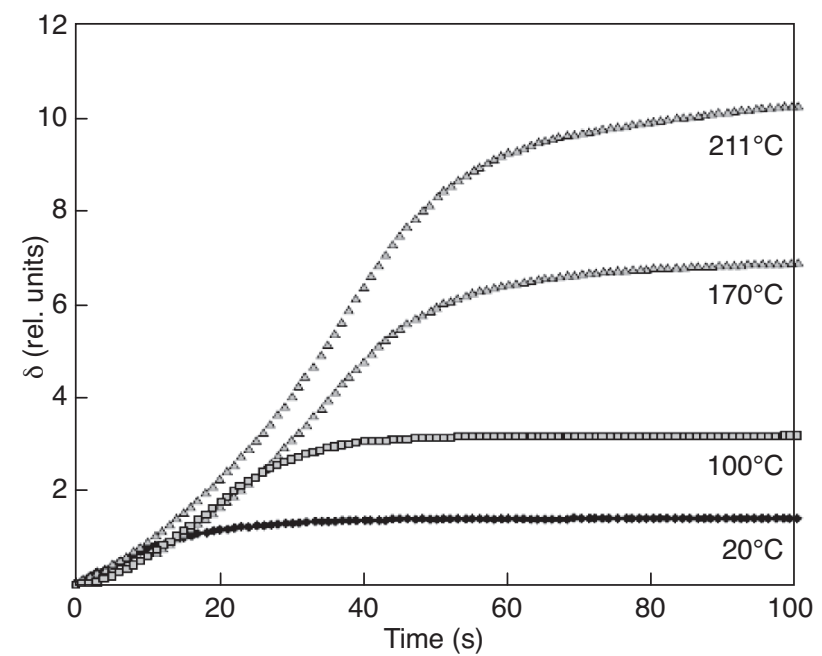

Figure 18

Dependence of the thickness of oxide layer on the surface of cobalt particles on time of oxidation for $10 \mathrm{wt} \% \mathrm{Co} / \mathrm{Al}_{2} \mathrm{O}_{3}$. 


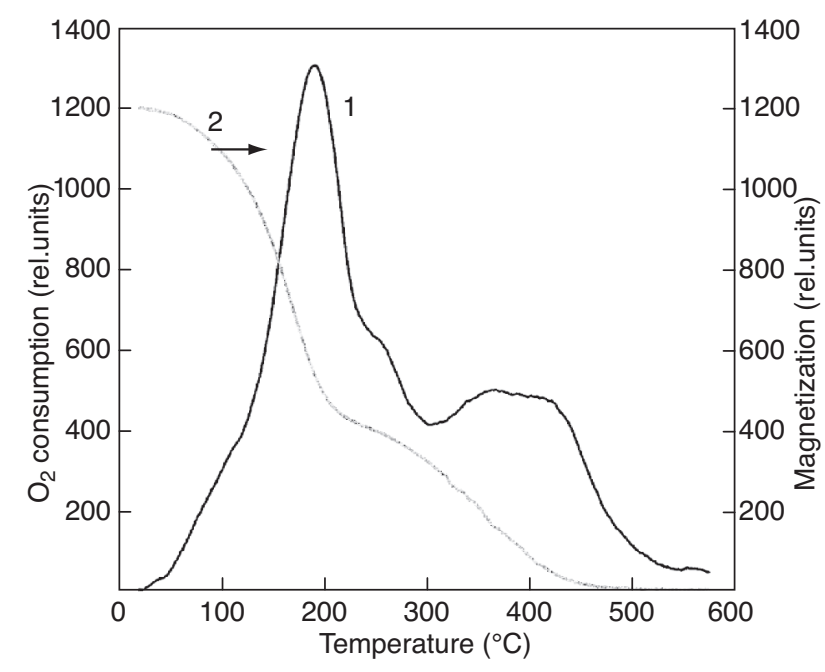

Figure 19

TPO profile of a $10 \mathrm{wt} . \% \mathrm{Co} / \mathrm{ZrO}_{2}+6 \% \mathrm{Y}_{2} \mathrm{O}_{3}$ catalyst.

\subsection{Measuring Cobalt Metal Particle Size}

Determination of sizes of cobalt particles is based on the relation between the magnetization and intensity of magnetic field. Below are summarized several methodologies which were used in our recent publications to determine cobalt metal particle sizes in supported catalysts.

First, the preliminary analysis of cobalt particle size distribution in cobalt-supported catalysts can be realized using variation in coercive force during mild oxidization (see also Sect.3). It is known that the coercive force increases with the size of single-domain cobalt particles and reaches $[12,19$, 42] a maximum for cobalt metal particles of about $20 \mathrm{~nm}$. Then the coercive force decreases to the limit typical of bulk metal cobalt. At relatively low temperatures, oxidation of cobalt metal particles follows a Cabrera-Mott mechanism (see Sect. 6.2) [92]. In this mechanism, the oxidation proceeds via formation of thin oxide layers on the surface of metal particles. Therefore, oxidation in mild conditions could reduce the apparent size of cobalt metal particles. If the average size of cobalt particles is larger than $20 \mathrm{~nm}$, the decrease in the apparent size of cobalt metal particles would result in an increase in coercive force. If the average size of cobalt particles is smaller than $20 \mathrm{~nm}$, the oxidation would lead to a decrease in coercive force. This technique allows qualitative ranking of cobalt-supported catalysts into two major groups: catalysts with larger cobalt particles $(>20 \mathrm{~nm})$ and catalysts with smaller cobalt particles $(<20 \mathrm{~nm})$.

The second method of evaluation of cobalt particle size distribution involves catalysts which contain only superparamagnetic and single-domain ferromagnetic cobalt particles.
In these catalysts the fraction of superparamagnetic particles can be estimated using Equation (20). This method was used to evaluate variation of cobalt particle size in monometallic and Pt-promoted cobalt alumina-supported catalysts [81]. Table 1 shows that promotion with Pt and higher catalyst reduction temperatures of monometallic cobalt alumina-supported catalysts result in an increase in the fraction of superparamagnetic particles and thus, in smaller average diameter of cobalt particle size. Some increase in the fraction of cobalt superparamagnetic particles upon promotion with $\mathrm{Ru}$ and $\mathrm{Re}$ was also observed [79] in silica-supported catalysts.

TABLE 1

Fraction of superparamagnetic cobalt particles in alumina-supported catalysts calculated using Equation (20) as a function of catalyst reduction temperature and promotion with $\mathrm{Pt}$

\begin{tabular}{|c|c|c|c|}
\hline Catalyst & $\begin{array}{c}\text { Catalyst } \\
\text { calcination } \\
\text { temperature }\end{array}$ & $\begin{array}{l}\text { Reduction } \\
\text { temperature } \\
\text { (K) }\end{array}$ & $\begin{array}{l}\text { Fraction of } \\
\text { super-paramagnetic } \\
\text { cobalt metal } \\
\text { particles in the } \\
\text { reduced catalysts } \\
(d<7 \mathrm{~nm})(\%)\end{array}$ \\
\hline \multirow{2}{*}{$\mathrm{Co} / \mathrm{Al}_{2} \mathrm{O}_{3}-473$} & \multirow{2}{*}{473} & 973 & 70 \\
\hline & & 673 & 66 \\
\hline \multirow{2}{*}{$\mathrm{Co} / \mathrm{Al}_{2} \mathrm{O}_{3}-613$} & \multirow{2}{*}{613} & 973 & 61 \\
\hline & & 673 & 60 \\
\hline \multirow{2}{*}{$\mathrm{Co} / \mathrm{Al}_{2} \mathrm{O}_{3}-673$} & \multirow{2}{*}{673} & 973 & 58 \\
\hline & & 673 & 54 \\
\hline \multirow{2}{*}{$\mathrm{Co} / \mathrm{Al}_{2} \mathrm{O}_{3}-773$} & \multirow{2}{*}{773} & 973 & 62 \\
\hline & & 673 & 56 \\
\hline \multirow{2}{*}{$\mathrm{Co} / \mathrm{Al}_{2} \mathrm{O}_{3}-473$} & \multirow{2}{*}{473} & 973 & 87 \\
\hline & & 673 & 90 \\
\hline \multirow{2}{*}{$\mathrm{Co} / \mathrm{Al}_{2} \mathrm{O}_{3}-773$} & \multirow{2}{*}{773} & 973 & 71 \\
\hline & & 673 & 77 \\
\hline
\end{tabular}

* Reduction in pure hydrogen, ramp $28.2 \mathrm{~K} / \mathrm{min}$.

The third method of particle size analysis addresses catalysts which contain only superparamagnetic catalysts. In these catalysts the cobalt particle size can be obtained by fitting the field dependence curves using the Langevin formula (Equation (8)). Barbier and Dalmon et al. [37, 93-94] showed that small cobalt particles could be prepared in silica-supported catalysts using the ammonia method. The magnetic method revealed that these small cobalt metal particles had superparamagnetic properties. The particle size distributions in these catalysts were measured using the Langevin function. The magnetic data were consistent with the results of transmission electron microscopy. The catalytic performance in $\mathrm{CO}+\mathrm{H}_{2}$ reaction as a function of Co average particle size showed that the reaction rate 
(expressed per metallic surface area) presented a maximum. Smaller particles were not efficient towards CO conversion and chain growth. This was related to the so-called ensemble effect [95].

Impregnation of silica with cobalt acetate solution also results in cobalt superparamagnetic particles [79]. Figure 20 presents the field dependences measured for the catalysts prepared from cobalt acetate. The field dependence without hysteresis loop is indicative of the presence of only superparamagnetic metal particles in these catalysts. The size of cobalt metallic particles was estimated using Equation (8). The calculation yields the size of superparamagnetic particles in the range of 3-6 nm.

The superparamagnetic particles can also be obtained in silica-supported catalysts prepared using addition of sucrose during co-impregnation with solutions of cobalt nitrate and ruthenium or rhenium precursors [79]. The hysteresis loops observed in these catalysts without sucrose addition suggest the presence of single-domain and multidomain ferromagnetic particles (Fig. 21a). This indicates the large size of cobalt particles. Addition of sucrose to the impregnating solution results in a major increase in cobalt dispersion. Mostly superparamagnetic particles were detected in these catalysts after their reduction in hydrogen. The calculation yields cobalt particle size of $4 \mathrm{~nm}$ for cobalt silica-supported catalysts promoted with rhenium and sucrose. The relevant

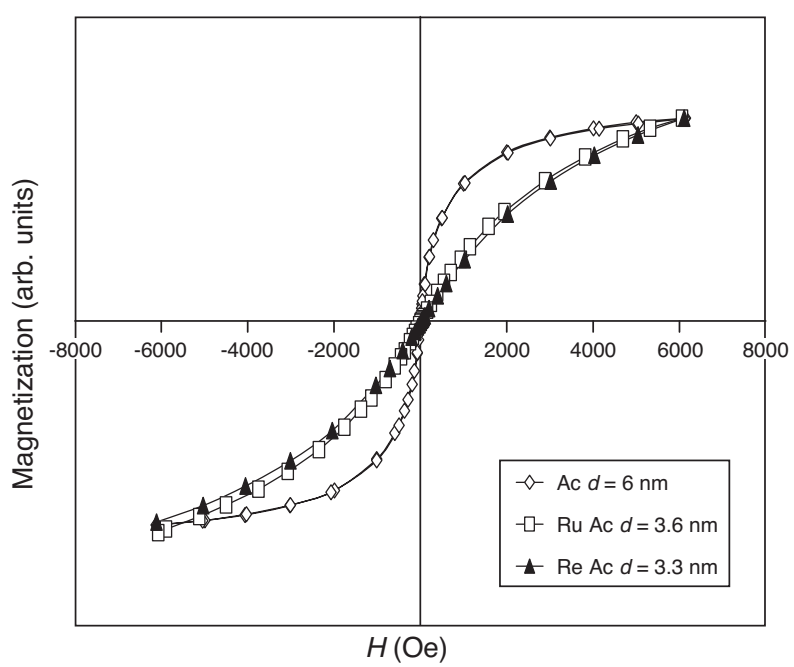

Figure 20

Field dependences measured for cobalt silica-supported catalysts prepared from cobalt acetate: (Ac) monometallic $\mathrm{Co} / \mathrm{SiO}_{2},(\mathrm{RuAc}) \mathrm{CoRu} / \mathrm{SiO}_{2},(\mathrm{ReAc}) \mathrm{CoRe} / \mathrm{SiO}_{2}$. The catalysts were obtained via soft decomposition of cobalt acetate at $443 \mathrm{~K}$. The cobalt particle sizes in the reduced catalysts were calculated from the Langevin formula (Equation (8)). cobalt $\mathrm{Ru}$-promoted catalyst prepared with sucrose addition probably contains both superparamagnetic and single-domain ferromagnetic particles (Fig. 21b). The calculation using Equation (20) estimates as $97 \%$ the fraction of superparagmanetic particles in this catalyst. The fraction of singledomain ferromagnetic particles in this sample is therefore lower than $3 \%$. Assuming that $3 \%$ of single-domain ferromagnetic particles do not disturb to a larger extent the field dependence curve, the evaluation using the Langevin function (Equation (8)) yields $6 \mathrm{~nm}$ for cobalt metal particle size in $\mathrm{CoRu} / \mathrm{SiO}_{2}$ prepared with sucrose addition.
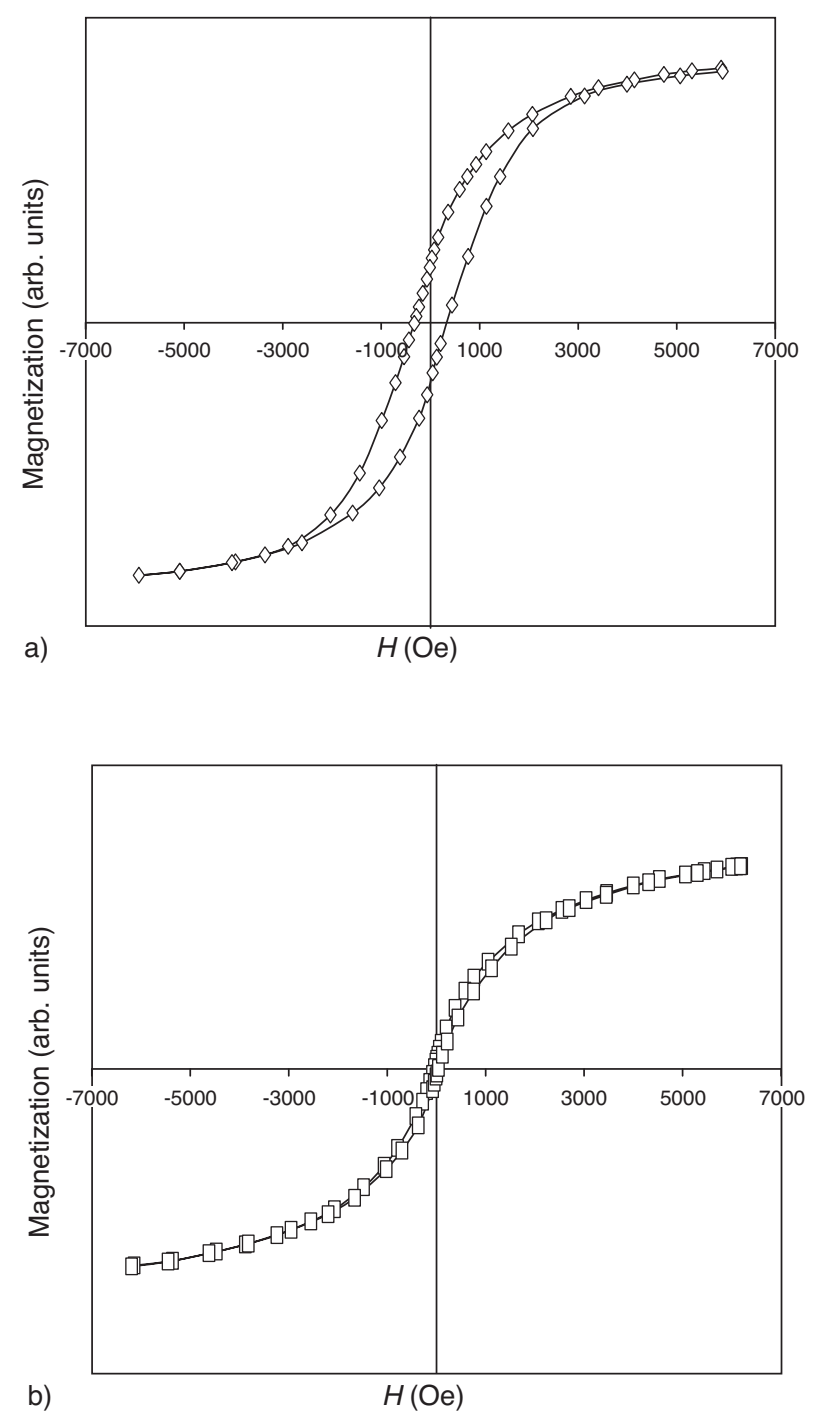

Figure 21

Field dependences measured for $\mathrm{CoRu} / \mathrm{SiO}_{2}$ catalysts prepared without a) and with b) addition of sucrose. Reprinted from [112] with permission from Elsevier. 
Smaller cobalt superparamagnetic particles can also be prepared in alumina-supported catalysts using decomposition of cobalt nitrate in glow discharge plasma [96]. The experimental procedure was similar to that previously applied to nickel catalysts [97]. The supports were impregnated with cobalt nitrate and dihydrogen hexachloroplatinate and dried at $373 \mathrm{~K}$. Then, the plasma treatment in mild conditions was performed, at nearly room temperature for 45 minutes in nitrogen plasma for decomposition, and for another $45 \mathrm{~min}$ utes in hydrogen plasma for reduction. The catalysts were reduced at $673 \mathrm{~K}$ in hydrogen flow. The relevant field dependence curves exhibit [96] the sigmoid shape characteristic of superparamagnetic particles with an average cobalt particle size of about $5 \mathrm{~nm}$.

The preparation recipe may play a key role in the final Co dispersion. $\mathrm{A} \mathrm{Co} / \mathrm{Al}_{2} \mathrm{O}_{3}$ catalyst prepared by coprecipitation and reduced at $773 \mathrm{~K}$ shows a large fraction of ferromagnetic particles blocked at room temperature (ca. $30 \mathrm{wt} . \%$ ) [87]. When $\mathrm{Cu}$ is introduced during the coprecipitation, the system is superparamagnetic (average particle size $4 \mathrm{~nm}$ ). This effect has been related to the higher dispersion of the Co oxide phase in the precursor, before reduction [87]. Such an effect of $\mathrm{Cu}$ addition has not been observed in the case of conventional impregnation of $\mathrm{Co}$ and $\mathrm{Cu}$ [98].

\section{COMPARISON OF MAGNETIC METHODS AND OTHER TECHNIQUES OF CATALYST CHARACTERIZATION}

The magnetic method is particularly sensitive to the presence of ferromagnetic phases in cobalt, iron and nickel catalysts. Three sorts of information about catalyst structure can be obtained:

- about the overall fraction of ferromagnetic phases,

- about size and size distribution of ferromagnetic particles,

- about the mechanism of formation of different carbide and oxide phases in iron catalysts.

Variation in magnetization during chemisorption can provide information about the stoichiometry of chemisorption, in particular for nickel catalysts. Saturation magnetization allows quantitative evaluation of the fraction of the cobalt metal phase and thus the extent of cobalt reduction in both transient and steady state conditions during different pretreatments and catalytic reaction. Measuring field dependences (magnetization versus magnetic field) could provide essential information about the sizes of ferromagnetic particles. The specificity of the magnetic method is that in many cases the information about catalyst structure can be obtained in situ when the sample has become inaccessible to other characterization techniques.

Temperature-programed reduction (TPR) is a common technique which can evaluate catalyst reducibility. The TPR methods, however, has several shortcomings. The reduction in TPR experiments is conducted in diluted hydrogen (typically $5-10 \% \mathrm{H}_{2}$ in inert gas), while the catalysts for catalytic measurements are typically reduced in pure hydrogen. It is known [79] that the rate and extent of reduction are to a greater extent affected by hydrogen partial pressure. Thus, the extent of reduction calculated from hydrogen consumption in TPR experiments could be much lower than the extent of reduction normally obtained during reduction in pure hydrogen. Note that the reduction of transition metal oxides often involves several steps, e.g. the reduction of $\mathrm{Co}_{3} \mathrm{O}_{4}$ to cobalt metallic phases usually proceeds via intermediate formation of $\mathrm{CoO}$ [99-101]. Thus, the attribution of hydrogen consumption peaks to different metal oxide reduction steps is often arbitrary in TPR experiments [102] and should always be confirmed by additional experimental evidence. In cobalt catalysts, only metallic cobalt has ferromagnetic properties. Thus, with cobalt catalysts the increase in magnetization is primarily due to the growth of cobalt metallic phases.

Several spectroscopic methods such as X-ray photoelectron spectroscopy (XPS), X-ray diffraction (XRD) and X-ray absorption (XANES/EXAFS) [103] also allow the measurement of the extent of reduction. The accuracy in measuring the extent of reduction depends, however, on the quality of the decomposition of spectra, which often represent a combination of signals coming from different reduced and oxidized phases. The experiments are commonly conducted with the reduced catalysts in quasi-steady state conditions, while the magnetic method can detect magnetization variation in the catalyst transient state. The rapid development of time-resolved spectroscopy such as dispersive EXAFS and Quick-EXAFS [104] can possibly overcome some of these difficulties.

The magnetic method also provides quantitative information about particle sizes and particle size distribution. Unfortunately, the particle size can only be estimated qualitatively when the catalysts contain both single-domain and multidomain ferromagnetic particles. It is known that XRD, TEM, XPS and EXAFS also provide information about metal particle size in the supported catalysts. The principal drawback of particle size evaluation from XRD profiles using the Scherrer equation or Williamson-Hall method [105] is due to the polycrystallinity of small metal and oxide particles in supported catalysts. The accuracy in evaluation of the crystallite sizes smaller than $6 \mathrm{~nm}$ from XRD data is rather low because of significant broadening of the diffraction patterns.

Evaluation of particle size from transmission and scanning electron microscopy requires uniform catalyst samples [106]. Sample heterogeneity can introduce dramatic effect on the quality of particle size evaluation. In the samples with high metal contents, the presence of agglomerates makes it difficult to obtain sufficient contrast and to measure the sizes of primary metal particles. The electron beam could alter particle size [107], particularly when interacting with smaller 
metal particles. The electron measurements are usually conducted in ultrahigh vacuum or at very low pressures [106], while it is generally accepted that the presence of gaseous components can significantly modify catalyst structure.

The Kerkof-Moulijn [108] and Kuipers models [109] are commonly used for evaluation of nanoparticle sizes from XPS data. These models, however, are only valid for diluted samples (metal content $<10 \mathrm{wt} . \%$ ). In addition, the simultaneous presence of different oxidized and reduced phases can significantly complicate interpretation of XPS data. XPS is only sensitive to the surface and subsurface layers of the catalyst [110] and non-uniform distribution of active components with the catalyst grain can significantly affect the results of XPS analysis. EXAFS provides [103, 106] information about the sizes of metal particles smaller than 1-2 nm. For larger particles, however, the accuracy of this technique is much smaller due to very minor correlation between particle size and coordination number [111]. The chemisorption methods measure only the number of metal sites in the catalysts. The amount of adsorbed gas strongly depends on the stoichiometry of adsorption, which is often uncertain for metal catalysts. It is known that the number of metal sites in supported catalysts is a function of both metal reducibility and metal particle size. The chemisorption methods cannot, however, distinguish between contributions to the number of metal sites arising from variation in metal dispersion or metal reducibility.

\section{CONCLUSION}

In summary, it could be argued that magnetic characterization in combination with conventional techniques, such as highresolution electron microscopy, X-ray absorption spectroscopy, $\mathrm{X}$-ray photoelectron spectroscopy, X-ray diffraction, temperature-programed reduction, temperature-programed oxidation, temperature-programed surface reaction and chemisorption provides additional and sometimes unique information about the catalysts which contain ferri- or ferromagnetic phases. Magnetization is very sensitive to the fraction of the ferromagnetic phase and the sizes of small ferromagnetic nanoparticles. It appears that the small ferromagnetic particles are often unstable in air. Thus, the use of in situ and operando experimental setups is highly recommended.

The magnetic method is particularly suited for cobaltcontaining catalysts. Only metallic cobalt has ferromagnetic properties. This simplifies the interpretation of magnetization data. The Curie temperature for cobalt is much higher than for iron and nickel. This allows investigation of small cobalt nanoparticles by the magnetic method in the conditions characteristic of most of the catalyst pretreatments and during catalytic reactions such as Fischer-Tropsch synthesis.

The uniqueness of metal-supported catalysts should also be emphasized in terms of physics of nanoparticles. In metal- supported catalysts with a high specific surface there is virtually no dipole-dipole magnetic interaction. This considerably facilitates investigation of these systems using the magnetic methods.

\section{ACKNOWLEDGMENTS}

The authors are grateful to Dr. G.V. Pankina for help with the experiments and data analysis. They also thank Professor V.V. Lunin and Dr. F. Diehl for fruitful discussions. P.A. C. acknowledges the financial support of the Russian Foundation for Fundamental Research (grant \# 06-03-32500-a).

\section{REFERENCES}

1 Khodakov A.Y., Chu W., Fongarland P. (2007) Advances in the development of novel cobalt Fischer-Tropsch catalysts for synthesis of long-chain hydrocarbons and clean fuels, Chem. Rev. 107, 1692-1744.

2 Iglesia E. (1997) Design, synthesis, and use of cobalt-based Fischer-Tropsch synthesis catalysts, Appl. Catal. A-Gen. 161, 59-78.

3 Dry M. (2002) The Fischer-Tropsch process: 1950-2000, Catal. Today 71, 227-241.

4 Chernavskii P.A., Lunin V.V. (1993) Oxide-oxide interaction in $\mathrm{Ni}, \mathrm{Co}$, and Fe supported catalysts, Kinet. Catal.+ 34, 470-477.

5 http://www.iupac.org/goldbook/T06395.pdf.

6 Selwood P.W. (1975) Chemisorption and Magnetization, Academic Press, New York.

7 Richardson J.T. (1978) Magnetism and catalysis, J. Appl. Phys. 49, 1781-1786.

8 Dalmon J.-A. (1994) Catalysts Characterization, Physical Techniques for Solid Materials, Plenum, New York, pp. 585-609.

9 Weiss P., Forrer R. (1926) Magnetization and Magnetocaloric Phenomena of Nickel, Ann. Phys. 5, 153-213.

10 Foner S. (1959) Versatile and Sensitive Vibrating-Sample Magnetometer, Rev. Sci. Instrum. 30, 548-557.

11 Chernavskii P.A. (2001) Topochemical processes in metal supported catalysts, Dr. Sci. thesis, Moscow State University.

12 Petrov Y.I. (1982) Physics of small particles, Moscow, Nauka, p. 327.

13 Frenkel J., Dorfman J. (1930) Spontaneous and Induced Magnetisation in Ferromagnetic Bodies, Nature 126, 274-275.

14 Kondorskii E.I. (1952) On the theory of single-domain particles, Doklady Academii Nauk SSSR 82, 365-368.

15 Kondorskii E.I. (1978) Micromagnetism and remagnetization of quasi-single-domain particles, Izvestiya Akademii Nauk SSSR, Seriya Fizicheskaya 42, 8, 1638-1645.

16 Brown W. F. Jr. (1963) Micromagnetics, Wiley-Inter., N.Y.

17 Kneller E. (1969) In Magnetism and Metallurgy, Academic Press, N.Y., Vol. 1, p. 365.

18 Sort J., Suriñach S., Muñoz J.S., Baró M.D., Wojcik M., Jedryka E., Nadolski S., Sheludko N., Nogués J. (2003) Role of stacking faults in the structural and magnetic properties of ball-milled cobalt, Phys. Rev. B 68,014421, 7 p. 
19 Pelecky D.L., Rieke D.R. (1996) Magnetic Properties of Nanostructured Materials, Chem. Mater. 8, 1770-1783.

20 Stoner E.C., Wohlfarth E.P. (1948) A Mechanism of Magnetic Hysteresis in Heterogeneous Alloys, Philos. T. Roy. Soc. A 240 , 599-642.

21 Chen C., Kitakami O., Shimada Y.J. (1998) Particle size effects and surface anisotropy in Fe-based granular films, J. Appl. Phys. 84, 2184-2188.

22 Neel L.C.R. (1949) Influence des fluctuations thermiques a l'aimantation des particules ferromagnétiques, C. R. Hebd. Seances Acad. Sci. 228, 664-668.

23 Weil L. (1954) Structure of catalysts and ferromagnetic properties at very low temperatures, J. Chim. Phys. Physico-Chimie Bio. 51, 715-717.

24 Wohlfarth E.P. (1980) The magnetic field dependence of the susceptibility peak of some spin glass materials, J. Phys. F: Met. Phys. 10, L241-L246.

25 Bean C.P., Livingston J.D. (1959) Superparamagnetism, J. Appl. Phys. 30, S120-S129.

26 Chen J.P., Sorensen C.M., Klabunde K.J. (1995) Enhanced magnetization of nanoscale colloidal cobalt particles, Phys. Rev. B $\mathbf{5 1}, 11527-11532$.

27 Billas M.L., Chatelain A., de Herr W.A. (1994) Magnetism from the Atom to the Bulk in Iron, Cobalt, and Nickel Clusters, Science 265, 1682-1684.

28 Sohl H., Bertram H.N. (1997) Localized surface nucleation of magnetization reversal, J. Appl. Phys. 82, 6128-6137.

29 Primet M., Dalmon J.A., Martin G.A. (1977) Adsorption of $\mathrm{CO}$ on well-defined $\mathrm{Ni} / \mathrm{SiO}_{2}$ catalysts in the $195-373 \mathrm{~K}$ range studied by infrared spectroscopy and magnetic methods, $J$. Catal. 46, 25-36.

30 Martin G.A. (1981) Détermination des tailles de particules métalliques et de leur distribution en catalyse hétérogène, Rev. Phys. Appl. 16, 181-192.

31 Estournes C., Lutz T., Happich J., Quaranta T., Wissler P., Guille J.L. (1997) Nickel nanoparticles in silica gel: Preparation and magnetic properties, J. Magn. Magn. Mater. 173, 83-92.

32 Richardson J.T., Desai P. (1976) Ultrahigh magnetic field measurements of nickel crystallite size distributions, J. Catal. 42, 294-302.

33 Potton J.A., Daniell G.J., Eastop A.D., Kitching M., Melville D., Poslad S., Rainford B.D., Stanley H. (1983) Ferrofluid particle size distributions from magnetisation and small angle neutron scattering data, J. Magn. Magn. Mater. 39, 95-98.

34 Skilling J., Bryan R.K. (1984) Maximum-entropy image-reconstruction - general algoritm, Mon. Not. R. Astron. Soc. 211, 111.

35 Zolla H.G., Spaepen F. (1995) Size distribution of Ni precipitates in Ag-Ni alloys determined by maximum entropy analysis of magnetization curves, Mater. Sci. Eng. A 204, 71-75.

36 Attila Kákay, Gutowski M.W., Takacs L., Franco V., Varga L.K. (2004) Langevin granulometry of the particle size distribution, $J$. Phys. A: Math. Gen. 37, 6027-6042

37 Lermontov A., Dalmon J.-A., Miachon S., van Berge P.J., van de Loosdrecht J. (2002) TEM and magnetic characterization of well-dispersed $\mathrm{Co} / \mathrm{SiO}_{2}$ catalysts. Abstract CATSA 2002.

38 De Montgolfier P., Martin G.A., Dalmon J.-A. (1973) Granulometry and metallic mass of finely divided ferromagnetic catalyzers calculated using magnetization/magnetic field curves, J. Phys. Chem. Solids 34, 801-812.
39 Dalmon J.-A., Martin G., Imelik B. (1973) Basic silicate of cobalt tale and antigorite - synthesis, morphologie, thermal decomposotion and reduction by hydrogen- granulometric study of cobalt on silica catalysts thus obtained, J. Chim. Phys. Physico-Chimie Bio 70, 214-224.

40 Kokorin V.V., Perekos A.E., Chuistov K.V. (1977) Magnetostatic interaction of ferromagnetic phase particles in non-ferromagnetic matrix, Fizika Metallov i Metallovedenie 43, 966-971.

41 Venttsel E.C., Ovcharov L.A. (1969) Theory of probability, Moscow, Nauka, p. 364.

42 Chernavskii P.A. (2005) Preparation of Fischer-Tropsch catalysts, Kinetics Catal. 46, 634-640.

43 Perov N.S., Sudarikova N.Yu., Bagrets A.A. (2003) The magnetic properties of the systems of the ultra-fine particles, $J$. Magn. (Korean Magn. Soc.) 8, 1, 7-12.

44 Perov N.S., Radkovskaya A.A. (2000) A Vibrating Sample Anisometer, Proceeding of 1 \& 2 Dimensional Magnetic Measurement and Testing, 20-21 Sept. 2000, Bad Gastein, ISBN 3-902105, p. 104.

45 Yakushiji K., Mitani S., Takanashi K., Ha J.-G., Fujimori H. (2000) Composition dependence of particle size distribution and giant magnetoresistance in Co-Al-O granular films, J. Magn. Magn. Mater. 212, 75-81.

46 Weissmuller J., Michels A., Barker J.G., Wiedenmann A., Erb U., Shull R.D. (2001) Analysis of the small-angle neutron scattering of nanocrystalline ferromagnets using a micromagnetics model, Phys. Rev. B 63, 2144141-21441418.

47 Brown W.F. Jr. (1969) The fundamental theorem of the theory of fine ferromagnetic particles, Ann. NY Acad. Sci. 147, 463-488.

48 Dormann J.L., Fiorani D, Tronc E. (1997) Magnetic relaxation in fine-particle systems, $A d v$. Chem. Phys. 98, 283-494.

49 Dalmon J.-A., Martin G.A., Imelik B. (1974) Adsorptions de $\mathrm{H}_{2}$ et de $\mathrm{O}_{2}$ sur des alliages $\mathrm{Ni}$---Cu divisés supportés sur $\mathrm{SiO}_{2}$, etudiées par mesure d'aimantation à saturation, Surf. Sci.41, 587-590.

50 Selwood P.W. (1975) Chemisorption and Magnetization, Academic Press, New York.

51 Martin G.A., Imelik B. (1974) Adsorption of hydrocarbons and various gases on $\mathrm{Ni}-\mathrm{SiO}_{2}$ catalysts studied by high field magnetic methods, Surf. Sci. 42, 157-172

52 Dalmon J.-A., Primet M., Martin G.A., Imelik B. (1975) Magnetic and infrared study of CO chemisorption on silica supported nickel-copper alloys, Surf. Sci. 50, 95-108.

53 Reuel R.C., Bartholomew C.H. (1984) The stoichiometries of $\mathrm{H}_{2}$ and $\mathrm{CO}$ adsorptions on cobalt: Effects of support and preparation, J. Catal. 85, 63-77.

54 Zowtiak J.M., Bartholomew C.H. (1983) The kinetics of $\mathrm{H}_{2}$ adsorption on and desorption from cobalt and the effects of support thereon, J. Catal. 83, 107-120.

55 Abeledo C.R., Selwood P.W.J. (1962) Chemisorption of hydrogen on cobalt, J. Chem. Phys. 37, 2709.

56 Dalmon J.-A., Martin G.A., Imelik B. (1974) Adsorption of $\mathrm{H}_{2}$ on $\mathrm{Ni}-\mathrm{Cu}$ alloys studied by magnetic measurements, Jpn. J. Appl. Phys. Suppl. 2, Part 2, 261-264.

57 Dumesic J.A., Topsoe H., Boudart, M. (1975) Surface, catalytic and magnetic properties of small iron particles: III. Nitrogen induced surface reconstruction, J. Catal.37, 513-522. 
58 Dutartre R., Bussière P., Dalmon J.-A., Martin G.A. (1979) Activation of hydrogen on $\mathrm{Fe} / \mathrm{MgO}$ catalysts studied by magnetic methods and Mössbauer spectroscopy, J. Catal. 59, 383394

59 Chernavskii P.A., Kiselev V.V., Kuprin A.P., Grechenko A.N., Baranaova L.I., Lunin V.V. (1991) Characteristics of hydrogen reduction of iron-oxide applied on silica-gel, Russ. J. Phys. Chem. 65, 1675-1679.

60 Chernavskii P.A., Kiselev V.V., Lunin V.V. (1992) Mechanism of the reduction of iron-oxides applied on silica gel, Russ. $J$. Phys. Chem. 66, 2712-2718.

61 Chernavskii P.A., Pankina G.V., Zavalishin I.N., Lunin V.V. (1994) The kinetics of reduction of iron oxides supported on $\mathrm{SiO}_{2}, \mathrm{Al}_{2} \mathrm{O}_{3}, \mathrm{ZrO}_{2}$ by hydrogen, Kinetics Catal. 35, 111-113.

62 Chernavskii P.A., Pankina G.V., Lunin V.V. (1998) Temperature-programmed reduction of $\mathrm{Fe}_{2} \mathrm{O}_{3} / \mathrm{Al}_{2} \mathrm{O}_{3}$ and $\mathrm{Pt} / \mathrm{Fe}_{2} \mathrm{O}_{3} / \mathrm{Al}_{2} \mathrm{O}_{3}$ catalysts, Russ. J. Phys. Chem. 72, 2086-2088.

63 Wielers A.F.H., Kock A.J.H.M., Hop C.E.C.A., Geus J.W., van der Kraan A.M. (1989) The reduction behavior of silica-supported and alumina-supported iron catalysts: A Mössbauer and infrared spectroscopic study, J. Catal. 117, 1-18.

64 Wang C.J., Ekerdt J.G.J. (1983) Study of Fischer-Tropsch synthesis over $\mathrm{Fe} / \mathrm{SiO}_{2}$ : Reactive scavenging with pyridine and cyclohexene, J. Catal. 80, 172-187.

65 Amelse J.A., Butt J.B., Schwartz L.H.J. (1978) Carburization of supported iron synthesis catalysts, J. Phys. Chem. 82, 558-563.

66 Rozovskii A.Y. (1989) Heterogeneous catalytic reactions: Kinetics and macrokinetics, Moscow, Nauka, p. 323.

67 Bartolomew C.H. (1988) Hydrogen effect in catalysis. Fundamental and practical applications. Role of hydrogen in CO hydrogenation, Dekker, Basel, NY, p. 543.

68 Matsumoto H., Bennett C.O. (1978) The transient method applied to the methanation and Fischer-Tropsch reactions over a fused iron catalyst, J. Catal. 53, 331-344.

69 Loktev S.M., Makarenkova L.I., Slivinskii E.V., Entin S.D. (1972) Thermomagnetic analysis of fused iron catalysts for synthesis of higher alcohols from carbon monoxide and hydrogen, Kinetics Catal. 13, 1042-1049.

70 Niemantsverdriet J.W., van der Kraan A.M., van Dijk W.L., van der Baan H.S. (1980) Behavior of metallic iron catalysts during Fischer-Tropsch synthesis studied with Moessbauer spectroscopy, X-ray diffraction, carbon content determination, and reaction kinetic measurements, J. Phys. Chem. 84, 3363-3370.

71 Unmuth E.E., Schwartz L.H., Butt J.B. (1980) Iron alloy Fischer-Tropsch catalysts: I: Carburization studies of the $\mathrm{Fe}---\mathrm{Ni}$ system, J. Catal. 63, 404-414.

72 Chernavskii P.A., Pankina G.V., Lunin V.V. (1996) Carbidizing of iron deposited on $\mathrm{SiO}_{2}$ and $\mathrm{Al}_{2} \mathrm{O}_{3}$ in Fischer-Tropsch synthesis, Russ. J. Phys. Chem. 70, 1016-1021.

73 Chernavskii P.A., Lunin V.V. (1996) Kinetics of Iron Carbide Formation in Hydrogenation of $\mathrm{CO}$ over a Potassium-promoted $\mathrm{Fe} / \mathrm{SiO}_{2}$ Catalyst, Kinetics Catal.37, 850-854.

74 Chernavskii P.A. (1997) The carburization kinetics of iron-based Fischer-Tropsch synthesis catalysts, Catal. Lett. 45, 215-219.

75 Ichiyanagi Y., Yamada S. (2005) The size-dependent magnetic properties of $\mathrm{Co}_{3} \mathrm{O}_{4}$ nanoparticles, Polyhedron 24, 2813-2816.
76 Romero J., Jiménez J., Del Cerro J. (2004) Calorimetric investigation on the paramagnetic-antiferromagnetic phase transition in CoO, J. Magn. Magn. Mater. 280, 257-263.

77 Bedel L., Roger A.C., Estournes C., Kiennemann A. (2003) Co ${ }^{0}$ from partial reduction of $\mathrm{La}(\mathrm{Co}, \mathrm{Fe}) \mathrm{O}_{3}$ perovskites for FischerTropsch synthesis, Catal. Today 85, 207-218.

78 Bedel L., Roger A.-C., Rehspringer J.-L., Zimmermann Y., Kiennemann A. (2005) $\mathrm{La}_{(1-y)} \mathrm{Co}_{0.4} \mathrm{Fe}_{0.6} \mathrm{O}_{3 \text {-delta }}$ perovskite oxides as catalysts for Fischer-Tropsch synthesis, J. Catal. 235, 279294.

79 Chernavskii P.A., Khodakov A.Y., Pankina G.V., Girardon J.-S., Quinet E. (2006) In situ characterization of the genesis of cobalt metal particles in silica-supported Fischer-Tropsch catalysts using Foner magnetic method, Appl. Catal. A 306, 108-119.

80 Chernavskii P.A., Lermontov A.S., Pankina G.V., Torbin S.N., Lunin V.V. (2002) Effect of the $\mathrm{ZrO}_{2}$ pore structure on the reduction of a supported cobalt oxide in catalysts for FischerTropsch synthesis, Kinetics Catal. 43, 268-274

81 Chu W., Chernavskii P.A., Gengembre L., Pankina G.A., Fongarland P.A., Khodakov A.Y. (2007) Cobalt species in promoted cobalt alumina-supported Fischer-Tropsch catalysts, $J$. Catal. 252, 215-230.

82 Girardon J.-S., Lermontov A.S., Gengembre L., Chernavskii P.A., Griboval-Constant A., Khodakov A.Y. (2005) Effect of cobalt precursor and pretreatment conditions on the structure and catalytic performance of cobalt silica-supported Fischer-Tropsch catalysts, J. Catal. 230, 339-352.

83 Girardon J.-S., Constant-Griboval A., Gengembre L., Chernavskii P.A., Khodakov A.Y. (2005) Optimization of the pretreatment procedure in the design of cobalt silica supported Fischer-Tropsch catalysts, Catal. Today 106, 161-165.

84 Kissinger H.E. (1957) Reaction kinetics in differential thermal analysis, Anal. Chem. 29, 1703-1706.

85 Grandvallet P., Courty Ph., Freund E. (1984) Characterization and catalytic properties of copper-cobalt-aluminium-zinc mixed phases for higher alcohol synthesis, Proc. of the 8th Int. Cong. on Catal., Springer Verlag, Berlin, II, pp. 81-92.

86 Courty Ph., Chaumette P., Raimbault C., Travers Ph. (1990) Production of methanol-higher alcohol mixtures from natural gas via syngas chemistry, Revue I.F.P. 45, 4, 561-578.

87 Dalmon J.-A., Chaumette P., Mirodatos C. (1992) Higher alcohols synthesis on cobalt based model catalysts, Catal. Today $\mathbf{1 5}$, 101-127.

88 van de Loosdrecht J., Balzhinimaev B., Dalmon J.-A., Niemantsverdriet J.W., Tsybulya S.V., Saib A.M., van Berge P.J., Visagie J.L. (2007) Cobalt Fischer-Tropsch synthesis: Deactivation by oxidation? Catal. Today 123, 293-302.

89 Bremaud M., Fongarland P., Anfray J., Jallais S., Schweich D., Khodakov A.Y. (2005) Influence of syngas composition on the transient behavior of a Fischer-Tropsch continuous slurry reactor, Catal. Today 106, 137-142.

90 van Steen E., Clayes M., Dry M.E., van de Loosdrecht J., Vilkoen E.L., Visagie J.L. (2005) Stability of nanocrystals: Thermodynamic analysis of oxidation and re-reduction of cobalt in water/hydrogen mixtures, J. Phys. Chem. B 109, 3575-3677.

91 Hauffe K. (1963) Reactions in solids and at their surface, Russian translation, Moscow, IL, Vol. 2, p. 275. 
92 Cabrera N., Mott N.F. (1948) The theory of the oxidation of metals, Rep. Prog. Phys. 12, 163-184.

93 Barbier A., Tuel A., Arcon I., Kodre A., Martin G.A. (2001) Characterization and catalytic behavior of $\mathrm{Co} / \mathrm{SiO}_{2}$ catalysts: Influence of dispersion in the Fischer-Tropsch reaction, $J$. Catal. 200, 106-116.

94 Barbier A., Hanif A., Dalmon J.-A., Martin G.A. (1998) Preparation and characterization of well-dispersed and stable $\mathrm{Co} / \mathrm{SiO}_{2}$ catalysts using the ammonia method, Appl. Catal. AGen. 168, 333-343.

95 Martin G.A., Dalmon J.-A., Mirodatos C. (1984) Particle sizesensitivity in catalysis by nickel: a statistical approach based on the combined effect of surface coverage and active dimension site, Proc. 8th Int. Cong. Catal., Berlin 1984, Dechema, IV, pp. 371-380.

96 Chu W., Wang L.-N., Chernavskii P.A., Khodakov A.Y. (2008) Glow discharge plasma assisted design of cobalt catalysts for Fischer Tropsch synthesis, Angew. Chem. Int. Edit. 47, 5052-5055.

97 Zhang Y., Chu W., Cao W., Luo C., Wen X., Zhou K. (2000) A plasma-activated $\mathrm{Ni} /$ alpha- $\mathrm{Al}_{2} \mathrm{O}_{3}$ catalyst for the conversion of $\mathrm{CH}_{4}$ to syngas, Plasma Chem. Plasma P. 20, 137-144.

99 Baker J.E., Burch R., Hibble S.J., Loader P.K. (1990) Properties of silica-supported $\mathrm{Cu}-\mathrm{Co}$ bimetallic catalysts in the synthesis of higher alcohols, Appl. Catal. 65, 281-292.

100 Khodakov A., Griboval-Constant A., Bechara R., Villain F. (2001) Pore-size control of cobalt dispersion and reducibility in mesoporous silicas, J. Phys. Chem. B 105, 9805-9811.

101 Khodakov A., Lynch J., Bazin D., Rebours B. Zanier N. Moisson B., Chaumette P. (1997) Reducibility of cobalt species in silica-supported Fischer-Tropsch catalysts, J. Catal. 168, 16-25.

102 Sewell G.S., van Steen E., O'Connor C.T. (1996) Use of TPR/TPO for characterization of supported cobalt catalysts, Catal.Lett. 37, 255-260.
103 Pichon C., Lynch J. (2005) Synchrotron radiation and oil industry research, Oil Gas Sci. Technol. 60, 735-746.

104 Newton M.A., Dent A.J., Fiddy S.G., Jyoti B., Evans J. (2007) Combining diffuse reflectance infrared spectroscopy (DRIFTS), dispersive EXAFS, and mass spectrometry with high time resolution: Potential, limitations, and application to the study of NO interaction with supported Rh catalysts, Catal. Today 126, 1-2, 64-72; Frahm R. (1988) Quick scanning EXAFS: First experiments, Nucl. Instrum. Meth. A 270, 2-3, 578-581.

105 Williamson G.K., Hall W.H. (1953) X-ray line broadening from filed aluminium and wolfram, Acta Metal. 1, 22-31.

106 Lynch J. (2002) Development of Structural Characterisation Tools for Catalysts, Oil Gas Sci.Technol.57, 281-305.

107 Pan M., Cowley J.M., Chan I.Y. (1990) HREM imaging of small Pt clusters dispersed in Y-zeolites, Catal.Lett. 5, 1-11.

108 Kerkhof F.P.J., Moulijn J.A. (1979) Quantitative analysis of XPS intensities for supported catalysts, J. Phys. Chem. 83, 1612-1619.

109 Kuipers H.P.C.E., Van Leuven H.C.E., Visser W.M. (1986) The characterization of heterogeneous catalysts by XPS based on geometrical probability. 1. Monometallic catalysts, Surf. Interface Anal. 8, 235-242.

110 Somorjai G.A. (1994) Introduction to Surface Chemistry and Catalysis, Willey, New York.

111 Benfield R. (1992) Mean coordination numbers and the nonmetal metal transition in clusters, J. Chem. Soc. Faraday Trans. 88, 8, 1107-1110.

112 Chu W., Chernavskii P.A., Gengembre L., Pankina G.A., Fongarland P., Khodakov A.Y. (2007) Cobalt Species in Promoted Cobalt Alumina-Supported Fischer-Tropsch Catalysts, J. Catal. 252, 215-230

Final manuscript received in September 2008 Published online in February 2009 or distributed for profit or commercial advantage and that copies bear this notice and the full citation on the first page. Copyrights for components of this work owned by others than IFP must be honored. Abstracting with credit is permitted. To copy otherwise, to republish, to post on servers, or to redistribute to lists, requires prior specific permission and/or a fee: Request permission from Documentation, Institut français du pétrole, fax. +33147527078 , or revueogst@ifp.fr. 